UNIVERSIDADE DE SÃO PAULO

FACULDADE DE FILOSOFIA, LETRAS E CIÊNCIAS HUMANAS

DEPARTAMENTO DE HISTÓRIA

PROGRAMA DE PÓS-GRADUAÇÃO EM HISTÓRIA SOCIAL

\title{
A CULTURA MATERIAL NA DIDÁTICA DA HISTÓRIA
}

\author{
Felipe Pascuet Pregnolatto
}

Dissertação apresentada ao Programa de Pós-Graduação em História Social, do Departamento de História da Faculdade de Filosofia, Letras e Ciências Humanas da Universidade de São Paulo, para obtenção do título de Mestre em História.

Orientadora: Prof ${ }^{a}$. Dra . Marlene Suano 


\title{
UNIVERSIDADE DE SÃO PAULO \\ FACULDADE DE FILOSOFIA, LETRAS E CIÊNCIAS HUMANAS DEPARTAMENTO DE HISTÓRIA \\ PROGRAMA DE HISTÓRIA SOCIAL
}

\section{A CULTURA MATERIAL NA DIDÁTICA DA HISTÓRIA}

\author{
Felipe Pascuet Pregnolatto
}




\section{DEDICATÓRIA}

Dedico essa dissertação aos meus pais, avós, irmão e à Juliana. 


\section{AGRADECIMENTOS}

Agradeço ao CNPq pelo financiamento que possibilitou essa dissertação, ao Departamento de História pelo empréstimo do notebook e à secretaria de pós graduação pelos serviços prestados.

Agradeço à professora Marlene por todo empenho, dedicação e principalmente pela paciência. Ao professor Ulpiano pela inspiração, pelos comentários e pela preciosa biblioteca. Aos professores Marcelo Rede e Ana Maria Camargo pelas sugestões feitas na banca de qualificação.

Agradeço à Maria Luiza Otero e toda equipe do Grupamento de Papel e Celulose do IPT pela doação dos livros e suporte técnico.

Agradeço a Marily Ribeiro pelo empréstimo de livros e a Rafael Scopacasa por dividir a responsabilidade de ser orientado pela professora Marlene.

Agradeço meus amigos Ricardo Morila, Rafael Diorio, Nicholas Malferrari, David Starling, Gustavo Nogueira, Luiz Alves, Giancarlo Espósito, Guilhermo Gomes, Marcos Spinelli, Bernardo Spinelli, Ricardo Barufaldi, Eduardo Dantona e Bruno Pedrosa.

Agradeço aos professores e alunos do Colégio Casagrande pela vivência no ambiente escolar.

Agradeço ainda às famílias Pascuet, Pregnolatto e Malange por toda dedicação. 


\section{RESUMO}

A presente dissertação aponta o tratamento dado à Cultura Material nos livros didáticos de História. A amostra constitui-se de todos os livros didáticos aprovados pelo PNLD 2003, criando-se um banco de dados contendo todas as imagens neles contidas. Nesse banco de dados, as imagens são divididas em três categorias principais: vestígios arqueológicos, mediações interpretativas e fotos. A seguir, considera-se o meio (pintura a óleo, gravura, têmpera, aquarela, escultura, estruturas urbanas e rurais...) e o suporte (tela, mural, papel...) das imagens.

Tabulados e quantificados os dados, comparecem quadros indicativos por culturas e por problemas. Ausências e presenças são analisadas assim como as legendas das imagens e o manual do professor, constatando-se o uso ainda meramente ilustrativo da cultura material, que se explica por sugestões referentes à formação do historiador brasileiro.

\section{ABSTRACT}

The present work discusses the treatment material culture receives in history school books. The sample was constituted by all school books approved in 2003 by the PNLD program, from which a data bank was created, relating all images from the sample.In this data bank the images are divided in three main categories: archaeological data, photos and mediatic intermediate solutions. It is then considered the type(oil painting, sculpture, buildings,...) and the basis (canvas, paper, wall, stone...) for the images.

Organized and quantified the data, both cultures and problems are presented. The consideration of both presences and absences, as well as the analysis of labels and the teacher manual prompt us to suggest that the use still illustrative of material culture is much due to the background and schooling of the Brazilian historian. 


\section{PALAVRAS-CHAVE/KEY WORDS}

Cultura Material - Livro Didático - Ensino de História - Imagem - Antiguidade 


\section{ÍNDICE}

INTRODUÇÃO

CAPÍTULO I - O LIVRO DIDÁTICO, A CULTURA MATERIAL E A HISTÓRIA NO

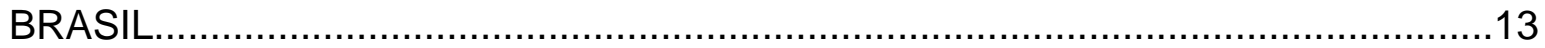

1.Estudos acadêmicos sobre o Livro Didático. ............................................... 15

2. Cultura material e Livro didático ................................................................. 21

3. Cultura material e História ………….................................................... 25

4. Imagem e ilustração no livro didático brasileiro ………….............................. 27

CAPÍTULO II - MATERIAL UTILIZADO E TABULAÇÃO DOS DADO ………......... 30

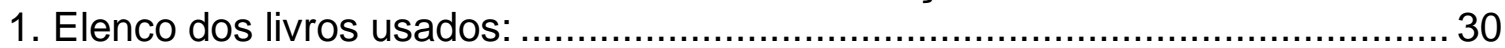

2. Quadro de categoriais de análise ........................................................... 30

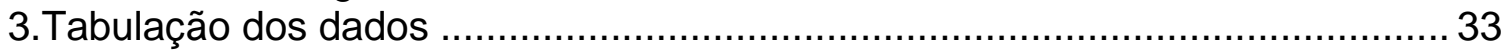

CAPÍTULO III - DE UMA IMPOSSÍVEL LEITURA DA CULTURA MATERIAL......43

1. A pré-história e a representação do documento..............................................43

2. Cultura Material e registros escritos ........................................................ 51

3. Recipientes de cerâmica.........................................................................61

4. Desenhos atuais e o uso pedagógico da imagem pelo historiador.....................70

CAPÍTULO IV - CONCLUSÕES - POR UMA POSSÍVEL LEITURA DA CULTURA

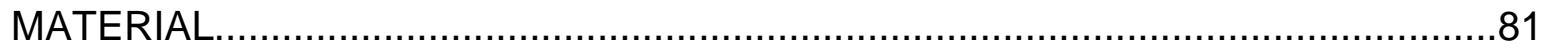

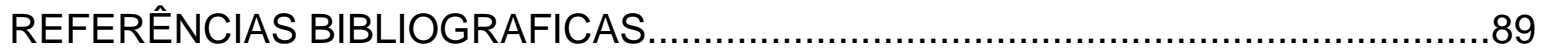




\section{A CULTURA MATERIAL NA DIDÁTICA DA HISTÓRIA}

\section{INTRODUÇÃO}

Há quase cem anos, os estudiosos - arqueólogos, antropólogos e, só recentemente, historiadores - vem procurando apontar não apenas as possibilidades de se produzir conhecimento histórico usando objetos como documentos - e não apenas textos, prática tradicional - como, também, a premente necessidade de fazê-lo.

O conceito de Cultura Material vem sendo moldado pelas modificações epistemológicas das ciências humanas, em um longo processo de "conquista de cidadania" (Pesez, 1974). Tomando corpo no bojo da estruturação das ciências sociais de meados do século $\mathrm{XIX}^{1}$, o uso de objetos como documentos históricos providenciava o "real", o "palpável", a "concretude" necessária ao discurso da ciência de então.

Arqueólogos da virada do século, primeiro o dinamarquês Sophus Muller, depois o alemão Gustav Kossinna, cunham o termo Cultura Arqueológica, a seguir difundido por Gordon Childe, para definir o conjunto de artefatos característicos de um determinado grupo humano. A Arqueologia pré-histórica francesa, em sua busca pelos Celtas/Gauleses, ajuda a solidificar a prática. A Arqueologia pré-histórica da Europa, nos trabalhos de seu maior expoente, V. Gordon Childe, serve de laboratório para a sedimentação do conceito ${ }^{2}$, à luz da abordagem marxista.

Em 1919, Lenin criava a Academia de História da Cultura Material e é no rastro das perspectivas marxistas que o conceito de Cultura Material ganha consistência, embora sob enfoque diverso daquele hoje corrente. Na França das

\footnotetext{
${ }^{1}$ Tylor (1870), Morgan (1877), Marx \& Engels(1848-1867).

2 Em sua produção de 1915 a 1958, finalizada no artigo póstumo "Prehistory and Marxism", in Antiquity, 1979, LIII: 93-97.
} 
primeiras tres décadas do século $X X$, a visão da historiografia sobre o rural, 0 econômico, a produção, o consumo, a tecnologia ${ }^{3}$, até hoje atuante, leva os historiadores franceses e, de certa forma, os marxistas em geral ${ }^{4}$ a fazer falar o que Bloch chamava de "os mudos da História". Tal abordagem, contudo, que tem em Braudel (1973) um de seus pilares, estuda a "civilização material" a partir de ... $\underline{\text { textos! }}$

Ou seja, entendia-se a história da cultura material como os processos de manutenção da vida econômica e material e ela era estudada, não a partir dos restos materiais de tal atividade mas, sim, pelo viés dos textos que a ela se referiam, enquanto que a Arqueologia, nessa mesma França, continuava buscando estudar a história do homem a partir dos objetos que ele produzia, em corrente liderada por Leroi-Gourhan ${ }^{5}$, ainda não de tudo afastada da prática arqueológica dos anos 40-50.

Enquanto a cultura material era vista como simples sinônimo de materialidade registrada em textos, a Arqueologia européia que buscava a história pelo viés dos objetos vê seu conceito de Cultura Arqueológica refutado pela Arqueologia americana dos anos 60 que, em extrema colaboração com a Antropologia, vê as limitações do conceito que oferecia suporte ao Difusionismo, mascarava problemas e oferecia explanações não aceitas pela moderna teoria antropológica.

Embora ainda desvinculada da História, a Arqueologia americana, com o apoio da anglo-saxônica, retorna ao conceito de CULTURA aos trilhos da Antropologia ${ }^{6}$ e propicia o crescimento, sobretudo nos EUA ${ }^{7}$, de estudos da cultura material no âmbito da documentação histórica. Tal vertente, contudo, raramente

\footnotetext{
${ }^{3}$ Produção a ser acompanhada em M.Bloch, L.Febvre, os "Annales" e os caminhos da "Nova História".(Duby,1988 ;Le Goff,1983,1990)

${ }^{4}$ Nos anos 50 funda-se, na Polônia, o Instituto de História da Cultura Material.

${ }^{5}$ Notável pré-historiador com obras publicadas nos anos 60-70.

${ }^{6} \mathrm{O}$ funcionalismo de Malinowski e de Radcliffe-Brown e o funcionalismo estrutural de seus discípulos, aliados à culture history da Antropologia americana,(MURDOCK, 1952, e tantos outros) vêem a cultura como um sistema integrado de segmentos autônomos, no qual a cultura material tem papel de destaque.

${ }^{7}$ Embora floresça, e com grande proveito, até na distante Índia (APPADURAI,A.(Ed),1986, The Social Life of Things, CUP), hoje considerado um dos clássicos do setor).
} 
conta com a participação dos historiadores propriamente ditos, ainda extremamente dependentes de textos (Rede, 1996:266).

Na Europa e na produção historiográfica de seus seguidores, seguramente importa o fato de que, nesse mesmo período, a Antropologia volta-se para a cultura enquanto expressão de sistemas da mente ${ }^{8}$ e os objetos continuam como parte da "civilização material" mas sem ter reconhecido seu potencial intrínseco de documentos históricos. ${ }^{9}$

Ora, as possibilidades da cultura material --- dos objetos eles próprios relacionados e referendados pela prática social --- proporem problemas históricos e encaminharem respostas a eles é tão vasta quanto a proporção de objetos que circulam na sociedade.

Extraordinariamente mais numerosos que os textos, sua não utilização como documentos históricos, pelos historiadores, suscita questões que, seguramente, residem na própria formação desses historiadores $\mathrm{e}$, conseqüentemente, nas diversas linhas em que a disciplina é trabalhada. E é essa formação do historiador, nunca desvinculada da estrutura sociocultural que a suporta, que a revela e nos norteia.

Nos últimos 40 anos, a produção de conhecimento histórico a partir dos objetos materiais (i.e. cultura material) tem crescido graças ao trabalho, sobretudo, de antropólogos e de arqueólogos. Ela pode ser seguida em suas vertentes da vida quotidiana (Goffman, 1959), da comunicação não-verbal (Hanneman, 1975; Polhemus, 1978; Burgoon, 1978; Harrison, 1989), do consumo (Douglas, 1979; Miller, 1987; McCracken, 1988), do espaço público e do espaço privado (Llorca, 1997; Chevalier, 1999) e das discussões teóricas mais amplas (Quimby, 1978;

\footnotetext{
${ }_{9}^{8}$ C.Lévi-Strauss e o estruturalismo dos anos 60-80.

9 Necessário acompanhar, nesse sentido, a produção francesa, tanto na Antropologia ROUESNEL,2001 (French Anthropology and Material Culture) quanto na chamada "Nova História" (DUBY,1988;LE GOFF,1983,1990).
} 
Rathje, 1979; Prown, 1980; Conrad, 1981, Schlereth, 1982;Schiffer, 1995), culminando com um periódico inglês --- Journal of Material Culture --- em existência desde 1996.

A rica produção - os exemplos acima são apenas norteadores - não chega, contudo, sequer a arranhar o primado da historiografia fincada nos textos, ainda erroneamente vistos como "os documentos históricos por excelência". A teoria da cultura material, que vê a possibilidade de estudar os objetos como vetores de relações sociais (Quimby, 1978; Rathje, 1979, Meneses 1983, 1993, 1994; Hodder 1989) e, portanto, documentos históricos de pleno direito, começa a sair do âmbito exclusivo da sociologia do consumo, da arqueologia e da antropologia e produzir resultados no âmbito da produção do conhecimento histórico.

Igualmente, a sugestão para que o interesse dos historiadores se desloque das fontes visuais (iconografia, iconologia) para um tratamento mais abrangente da visualidade como uma dimensão importante da vida social e dos processos sociais, como apontado por Meneses (2003: 11), infelizmente ainda não chegou plenamente ao ensino de História no nível superior e, em decorrência, claramente afeta os Livros didáticos. A formação disponível, contudo, já é suficiente para que se procure reverter esse quadro.

Pretendemos, com a presente dissertação, apontar o tratamento dado à Cultura Material nos livros didáticos de História, mostrando suas falhas e méritos, buscando assim contribuir para diminuir a distância entre a História acadêmica das universidades e a História ensinada nas escolas. Acreditamos que esse trabalho poderá ser de utilidade aos estudiosos das questões relacionadas ao ensino de História assim como aos autores de livros didáticos e professores do ensino fundamental e médio.

Assim é que, para buscar, na formação do historiador, o ponto atual da questão entre nós, decidimo-nos ver, na didática da veiculação dos conhecimentos 
historiográficos, o uso que recebe a cultura material e sugerir caminhos que viabilizem e potenciem seu uso enquanto documento histórico. 


\section{Capítulo 1 - 0 Livro Didático, a Cultura Material e a História no Brasil.}

Falar sobre a história do livro didático no Brasil porta em seu bojo, também, falar sobre a política do livro didático. Vem sendo consistentemente dito que "sua história não passa de uma seqüência de decretos, leis e medidas governamentais que se sucedem, a partir de 1930 de forma aparentemente desordenada, e sem a correção ou a crítica de outros setores da sociedade... Essa história da seriação de leis e decretos somente passa a ter sentido, quando interpretada à luz das mudanças estruturais como um todo, ocorridas na sociedade brasileira, desde o Estado Novo até a Nova República" (Freitag, Costa e Motta, 1989).

Mas a política do livro didático não é, contudo, o objetivo deste trabalho. Não se trata de abandoná-la mas de usá-la, isto sim, como base e contraponto para o estudo e discussão das questões metodológicas do uso da cultura material no livro didático.

Essa base começa a construir-se a partir de 1937, quando da primeira tentativa promovida pelo governo do Estado Novo para garantir a distribuição e divulgação de obras de interesse educacional, científico e cultural data de 1937 com a criação do INL (Instituto Nacional do Livro).

A primeira definição de livro didático data de 1938, com o Decreto Lei 1.006 no qual foi definido pela primeira vez o que vinha a ser o livro didático: ao estabelecer que Compêndios são livros que exponham total ou parcialmente a matéria das disciplinas constantes dos programas escolares.(art $2^{\circ}, \S 1^{\circ}$ ) e que Livros de leitura de classe são os livros usados para a leitura dos alunos em aula; tais livros também são chamados de livros de texto, livro-texto, compêndio escolar, livro de classe, manual, livro didático (art $2^{\circ} \S 2^{\circ}$; Oliveira, 1986). 
Durante as décadas seguintes foram criadas novas comissões, fundações e institutos que regulamentavam a produção e distribuição dos livros didáticos. Em 1945, o governo federal centralizou o poder de legislar sobre o livro didático. Foi no período da ditadura militar de 1964 que foram criadas a FENAME (Fundação Nacional de Material Escolar) e o programa de co-edição dos livros didáticos (Programa do Livro Didático -PLID) respectivamente em 1967 e 1970.

No decorrer da década de 80 ocorreu a liberalização da produção editorial, que se fortaleceu com a ampliação da rede pública de ensino. Em 1984 foi extinto o sistema de co-edição, e o MEC passou a ser comprador de livros didáticos. Em 1985 o Plid teve seus objetivos ampliados e mudou de nome passando a ser chamado de PNLD (Programa Nacional do Livro Didático) até 1995, quando sua responsabilidade se passa ao Fundo Nacional para Desenvolvimento da Educação (FNDE) que a mantém até o presente. Em 2006 iniciou-se a avaliação e distribuição de livros para o ensino médio.

Os parâmetros do programa são decisivos na construção do acervo de livros didáticos e baseia-se nos princípios da livre participação das editoras privadas e da livre escolha dos livros pelos professores, o que segundo seus gestores apresenta as seguintes vantagens (MEC, 2001):

A. Ampliação do atendimento. Até 1994 o Governo distribuía gratuitamente os livros até a quarta série do ensino fundamental. O PNLD ampliou a distribuição dos livros até a oitava série do ensino fundamental. A distribuição de dicionários também é um diferencial do PNLD.

B. Avaliação do livro didático. Órgão governamental realiza uma análise pedagógica dos livros que pretendem fazer parte do PNLD e divulga o resultado dessa análise no Guia de Livros Didáticos, que serve de base para que cada professor escolha o livro com que quer trabalhar. O Guia apresenta uma sinopse de 
cada título com uma classificação de qualidade e um formulário para os professores indicarem os livros que querem utilizar em sala de aula.

C. Pontualidade. A partir da consolidação de todos os pedidos o Governo inicia a negociação com as editoras que produzem os livros. Os livros são endereçados diretamente pelas editoras através de uma parceria do Ministério da Educação com a Empresa de Correios e Telégrafos.

D. Parâmetros Curriculares Nacionais. Os PCNs servem de orientação para autores, bem como guia para o processo de avaliação.

\section{Estudos acadêmicos sobre o Livro Didático.}

Nos últimos trinta anos, os livros didáticos vêm suscitando um interesse cada vez maior dos historiadores, transformando as edições didáticas em um domínio de pesquisa em pleno desenvolvimento. Esse aumento de interesse resulta da convergência de uma série de fatores conjunturais, como o crescente interesse dos historiadores profissionais pelo campo da educação; o interesse de diversas populações em recuperar uma identidade cultural, devido a acontecimentos recentes como a descolonização; o considerável progresso nas técnicas de armazenamento de dados e informações; a constituição de equipes e centros de pesquisa que se dedicam especificamente ao estudo das edições didáticas, entre as principais.

Recente estudo sobre livros didáticos (Choppin 2004)que vem merecendo o respeito dos especialistas no assunto, aponta quatro funções essenciais do livro didático, que podem, segundo seu autor, variar consideravelmente segundo o ambiente sócio-cultural, a época, as disciplinas, os níveis de ensino, os métodos e as formas de utilização:

"1. Função referencial, também chamada de curricular ou programática, desde que existam programas de ensino: o livro didático é então apenas a fiel tradução do 
programa ou, quando se exerce o livre jogo da concordância, uma das possíveis interpretações. Mas, em todo caso, ele constitui o suporte privilegiado dos conteúdos educativos, o depositório dos conhecimentos, técnicas ou habilidades que um grupo social acredita que seja necessário transmitir às novas gerações.

2. Função instrumental: o livro põe em prática métodos de aprendizagem, propõe exercícios ou atividades que, segundo o contexto, visam a facilitar a memorização dos conhecimentos, favorecer a aquisição de competências disciplinares ou transversais, a apropriação de habilidades, de métodos de análise ou de resolução de problemas, etc.

3. Função ideológica e cultural: é a função mais antiga. A partir do século XIX, com a constituição dos estados nacionais e com o desenvolvimento, nesse contexto, dos principais sistemas educativos, o livro didático se afirmou como um dos vetores essenciais da língua, da cultura e dos valores das classes dirigentes. Instrumento privilegiado de construção de identidade, geralmente ele é reconhecido, assim como a moeda e a bandeira, como símbolo da soberania nacional e, nesse sentido, assume um importante papel político. Essa função, que tende a aculturar - e, em certos casos, a doutrinar - as jovens gerações, pode se exercer de maneira explícita, até mesmo sistemática e ostensiva, ou, ainda, de maneira dissimulada, sub-reptícia, implícita, mas não menos eficaz.

4. Função documental: acredita-se que o livro didático pode fornecer, sem que sua leitura seja dirigida, um conjunto de documentos, textuais ou icônicos, cuja observação ou confrontação podem vir a desenvolver o espírito crítico do aluno. Essa função surgiu muito recentemente na literatura escolar e não é universal: só é encontrada - afirmação que pode ser feita com muitas reservas - em ambientes pedagógicos que privilegiam a iniciativa pessoal da criança e visam a favorecer sua autonomia; supõe, também, um nível de formação elevado dos professores". (Choppin 2004:553).

Choppin (2004) apontou também as principais dificuldades e limites da pesquisa relacionada ao livro didático, sendo que a primeira por ele apontada relaciona-se à própria definição do objeto. Na maioria das línguas, o "livro didático" é designado de diversas maneiras, e nem sempre é possível explicitar as características específicas que podem estar relacionadas a cada uma das 
denominações. A segunda dificuldade diz respeito ao caráter recente desse campo de pesquisa: as obras de síntese ainda são raras e não abrangem toda a produção didática ou todos os períodos; a produção científica que trata especificamente da história da literatura e das edições didáticas constitui-se essencialmente de artigos publicados em revistas ou livros. Outra dificuldade refere-se à recente inflação de publicações que se interessam pelo livro didático. Choppin (2004:550) constata "que mais de três quartos da produção científica têm menos de vinte anos e que 45\% têm menos de dez; em relação às 2 mil referências que temos hoje processadas em bancos de dados, referentes a aproximadamente cinqüenta países, corpus sobre o qual nos apoiamos, três quartos são posteriores a 1980 e mais da metade após 1990".

A produção acadêmica sobre as edições didáticas a que se refere Choppin (2004) trata aspectos extremamente diversos, mas que podem ser apresentados em duas grandes categorias de pesquisa:

o Aquelas que, concebendo o livro didático apenas como um documento histórico igual a qualquer outro, analisam os conteúdos em busca de informações estranhas a ele mesmo (a representação da ideologia colonial, por exemplo), ou as que só se interessam pelo conteúdo ensinado por meio do livro didático (história das categorias gramaticais, por exemplo). Neste caso o pesquisador não escreve a história do livro didático e sim a história de um determinado tema, de uma noção, de um personagem ou de como a literatura escolar foi apresentada por meio de uma mídia particular.

- Aquelas que, negligenciando os conteúdos dos quais o livro didático é portador, o consideram como um objeto físico, ou seja, como um produto fabricado, comercializado, distribuído ou, ainda, como utensílio concebido em função de certos usos, consumido - e avaliado - em um determinado contexto. Aqui o historiador dirige sua atenção diretamente 
para os livros didáticos, recolocando-os no ambiente em que foram concebidos, produzidos, utilizados e "recebidos", independente dos conteúdos dos quais eles são portadores.

Com referência ao Brasil, muitos estudos acadêmicos já foram feitos sobre o livro didático e, semelhantemente à amostragem internacional, a maioria deles se concentra na década de 1980, embora os estudos pioneiros datem da década de 1950. Esses estudos tratam de diversos assuntos como a economia do LD, a política do LD, embora predominem aqueles que têm na discussão do conteúdo do livro didático seu objetivo maior.

Duas grandes tendências podem ser apontadas na análise científica dos conteúdos dos livros didáticos brasileiros: A primeira diz respeito à crítica ideológica e cultural dos livros didáticos e é a mais recorrente nos estudos acadêmicos brasileiros. Estes estudos chegam, via de regra, a uma conclusão mais do que óbvia, aquela de não haver conhecimento neutro e, ainda, que os livros didáticos transmitem a ideologia da elite dominante ${ }^{10}$.

A segunda tendência analisa o conteúdo dos livros didáticos segundo uma perspectiva epistemológica ou propriamente didática. Esse tipo de análise ainda é mais comum em estudos relacionados aos livros de alfabetização e de ciências exatas, e discute os "mecanismos" didáticos utilizados nos livros. No caso dos livros de História, a análise nessa perspectiva critica ou defende o uso de recursos como a "linha do tempo", se o estudo deve ser temático ou cronológico, a utilização ou não da chamada "História Integrada" (conteúdos de história do Brasil e Geral no mesmo livro), etc.

Parte consistente dos estudos brasileiros é de difícil utilização e de escasso benefício, em função de amostragens sem critério, decorrentes de projetos que não consideram os LDs, documentos a serem analisados e, portanto, passíveis de

\footnotetext{
${ }^{10}$ A esse propósito, embora não pretendendo apresentar um elenco exaustivo ver CARMO(1992), KILSTAJN (1987), FRANCO(1981, 1982), PINSKY (1985), NOSELLA (1981), entre outros.
} 
seleção não-aleatória. A maior parte deles nem mesmo se preocupa em traçar o trajeto percorrido para se chegar ao material objeto de analise. A principal restrição que fazemos a esses estudos prende-se à subjetividade das amostragens trabalhadas, que não apenas prejudicam a aferição dos pontos abordados pelos autores de tais estudos como, sobretudo, impedem que qualquer outro trabalho prossiga a partir desses.

O estudo mais útil, a nosso ver, sobre a trajetória dos estudos acadêmicos sobre o livro didático foi feito por Freitag,Costa e Motta (1989). As autoras, ao comentarem os estudos que tratam do conteúdo no livro didático, os dividem naqueles que buscam os aspectos psico-pedagógicos, os que buscam os aspectos literários e os que buscam os aspectos ideológicos, servindo de base para outros estudos.

Quanto aos estudos sobre a História nos livros didáticos, eles apresentam as mesmas características dos estudos gerais sobre o livro didático. A mesma ausência de preocupação com a definição do corpo documental a ser utilizado no trabalho compromete seriamente os resultados obtidos. A maioria dos estudos trata da abordagem ideológica, tentando mostrar que os livros didáticos perpetuam a visão de mundo da elite ${ }^{11}$. Defendem que a maioria dos livros são tradicionalistas, refletem a "história oficial" e que não estão adequados às novas correntes historiográficas, que buscam resgatar o papel das camadas populares no processo histórico.

Este problema, contudo, não é novo. A observação de ser " ...lamentável que muitos manuaes continuem a repetir velhos erros... Um bom compendio deverá estar em dia com os resultados mais importantes da critica histórica e das pesquisas archeológicas , ethnologicas..." data de 1935 (Serrano,1935:68) e se constitui no início de um círculo vicioso, no qual os autores mais recentes fazem tabula rasa das contribuições passadas a começar, exatamente, de Serrano.

\footnotetext{
${ }^{11}$ Entre estes estudos estão os de Franco (1981, 1982),Davies(1996), Abud (1984), entre outros.
} 
Para estes autores ${ }^{12}$ defensores da idéia que o livro didático transmite a visão elitista de mundo, os livros seriam os responsáveis pela manutenção dos mitos e estereótipos impostos pela elite dominante. Um grande número deles afirma que essa maneira de se transmitir o conhecimento histórico faz com que a criança não produza reflexão sobre sua historicidade, ou seja, o aluno não se vê como partesujeito da História. A nosso ver essa crítica menospreza o papel do professor na sala de aula, já que este, ao utilizar o livro, poderia perfeitamente negar seu discurso, explicando ao aluno que aquela, por exemplo, é a visão da elite dominante, assim transformando o próprio livro em um documento histórico a ser analisado.

Acreditamos que os estudos acadêmicos sobre o livro didático não devam se restringir a questões relacionadas apenas ao conteúdo dos livros e principalmente ao conteúdo ideológico do livro didático. A necessidade de se estudar as diversas etapas da "vida" de um livro didático já foi apontada por Choppin (2004:553-554)

\begin{abstract}
"É preciso levar em conta a multiplicidade dos agentes envolvidos em cada uma das etapas que marca a vida de um livro escolar, desde sua concepção pelo autor até seu descarte pelo professor, e idealmente, sua conservação para as futuras gerações. A concepção de um livro didático inscreve-se em um ambiente pedagógico específico e em um contexto regulador que, justamente com o desenvolvimento dos sistemas nacionais ou regionais, é na maioria das vezes característico das produções escolares... Sua elaboração (documentação, escrita, paginação, etc.), realização material (composição, impressão, encadernação, etc.), comercialização e distribuição supõem formas de financiamento vultuosos, quer sejam públicas ou privadas...Por fim, sua adoção nas classes, seu descarte são capazes de mobilizar, nas sociedades democráticas sobretudo, numerosos parceiros (professores, pais, sindicatos, associações, técnicos, bibliotecários, etc.) e produzir debates e polêmicas".(Choppin 2004:553-554).
\end{abstract}

\footnotetext{
${ }_{12}$ Por exemplo Abud 1984; Carmo 1991; Faria 1984; Franco 1981, 1982; Kiliztajn 1997; Molina 1987; Pinsky 1985;
} 


\section{Cultura material e Livro didático}

Uma questão de conceito

É de fundamental importância aprofundarmos a definição do conceito de cultura material, em função da inexistência de oposição entre cultura material e imaterial. O que existe é uma dimensão material da cultura humana e, por material, devemos entender tudo aquilo que é apreendido pelos sentidos. Portanto, tanto uma cadeira, uma música ou uma ponte são parte da cultura material. O fato das funções sociais serem diferentes e o fato dos historiadores partirem de estruturas de informações escritas, usando a cultura material para corroborar e exemplificar o que já foi "dito e escrito", leva a um uso empobrecido e confuso das diferentes formas da cultura material, como veremos a seguir na discussão do material analisado. A única diferença na análise de uma ponte e um quadro é aquela relacionada com as características de cada objeto (para se estudar uma ponte são necessários conhecimentos sobre pedras, tijolos, cálculos de vão livre enquanto para se analisar um quadro os conhecimentos devem ser sobre pigmentos, perspectiva, vestimentas etc).

Baseamo-nos, em nosso trabalho, na definição de cultura material como sendo

....aquele segmento do meio físico que é socialmente apropriado pelo homem. Por apropriação social convém pressupor que o homem intervém, modela, dá forma a elementos do meio físico, segundo propósitos e normas culturais Essa ação, portanto, não é aleatória, casual, individual, mas se alinha conforme padrões, entre os quais se incluem objetos e projetos. Assim, o conceito pode tanto abranger artefatos, estruturas, modificações da paisagem, como coisas animadas (uma sebe, um animal doméstico), e também, o próprio corpo, na medida em que ele é passível desse tipo de manipulação ou, ainda os seus arranjos espaciais (um desfile militar, uma cerimônia litúrgica). Meneses (1983:112). 
Conforme este enquadramento, a cultura material deveria ser considerada sob um duplo aspecto: como produto e como vetor das relações sociais (Meneses 1980,1983, 1993, 1994; Rede 1996).

Como, então, o historiador lida com a questão da cultura material? Foram já apontadas três posturas marcantes da historiografia em relação à cultura material: a marginalização ou completa supressão do universo físico; o uso puramente instrumental dos aspectos da vida material (possivelmente a mais comum); e uso do universo material como ilustração daquilo que o texto já estabeleceu (Meneses,1983).

Essas posturas partem de algumas alegações equivocadas sobre a natureza da documentação material. Entre essas alegações está a de que existem fenômenos fundamentais do universo social que não se expressam materialmente. Outras alegações são a de que além de parcial, a documentação material chega em nossas mãos, no caso de documentos arqueológicos, após inúmeras triagens sem controle e a de que existe um fosso quase sempre intransponível entre o sítio arqueológico e o sistema cultural que o produziu.

De fato a diferença entre contexto sistêmico e o contexto arqueológico (formação post-abandono; Schiffer 1972), nos alerta não sobre a impossibilidade mas sobre a impropriedade de pensar-se em recuperar o contexto sistêmico, a partir do sistema arqueológico, sem os necessários filtros para entender descarte e deposição.

Para criticar essas posturas vem sendo apontado que:

"ressaltar o caráter "parcial" dos fenômenos materiais é estabelecer uma distinção que carece de fundamentos, entre os componentes materiais e não materiais da cultura, dando a esses últimos uma autonomia que eles não podem ter. Devemos estar cientes que a formulação dos diversos conceitos de cultura material está sempre ligada à visão que os autores têm da própria noção de cultura". (Meneses,1994:107). 
Contudo, os estudos de cultura material não se referem, evidentemente, apenas a restos arqueológicos, embora tenham começado, como já nos referimos, (vide p.08) ligados aos estudos de pré-história.

O essencial é buscar entender o que os objetos significam para a sociedade que os produziu e os utilizou enquanto que acreditar que a escrita delimita a história é reduzir o alcance da experiência humana. Yentsch \& Beaudry (2001) nos mostram em seu texto sobre arqueologia histórica na América do Norte que os resíduos materiais da interação de três culturas diferentes, a branca, a vermelha e a negra permitem o levantamento de questões sobre diversidade e influência cultural, características étnicas e os papéis dos indivíduos e dos grupos sociais na região, muito além das possibilidades de todos os textos pertinentes somados.

Os artefatos podem, pois, ser analisados pelas informações materiais que intrinsecamente comporta e por suas funções na sociedade, ocupando dois diferentes domínios culturais, existido ora como instrumento ora como símbolo e ainda ocupando as duas funções ao mesmo tempo.

Desde os primeiros estudos americanos, há muito a ser considerado e aprendido. Devemos olhar para os modelos de sepulturas criados por Deetz e Dethlefsen (1967), os estudos sobre casas populares de Glassie(1975) ou os estudos sobre cultura material na Nova Inglaterra feitos por Deetz (1977). Hume (1969) retirou das artes decorativas clássicas modelos para olhar pequenos objetos embutidos nas camadas estratigráficas dos sítios da Virgínia revolucionária. South (1977), a partir das experiências de Hume (1969), criou um sistema estatístico para cerâmicas, que lhe permitiu estabelecer cronologias e inferir um estilo de vida.

Dentre os estudos citados, o mais sofisticado é o de Glassie (1975). No centro de sua perspectiva estava a crença nas permanentes formas da cultura material e na expressiva performance associada com o trabalho do povo em uma tradição vernácula. Ele procurou capturar a essência da arte popular e como esta se mantinha em diferentes culturas, aceitando que o que era essencial poderia mudar em cada cultura.

Geertz (1973) argumentou persuasivamente em defesa de uma teia de cultura humana e contra qualquer priorização dos fatores econômicos, tecnológicos ou 
ambientais. Seu modelo posicionava a cultura como uma rede profunda, cujos componentes interligados eram conectados por uma variedade de grupos de relacionamentos, construídos por uma composição de valores religiosos, sociais, econômicos e tecnológicos. Nenhum fator isolado é determinante para o todo. Os indivíduos constroem múltiplos meios, ligados ao mundo material para dar sentido às suas vidas, criando inovações e/ou conservando a tradição. Toda cultura seria, assim, cercada por diversos agentes, que deixam suas impressões nas comunidades em uma variedade de materiais. Os valores são culturais. Processos culturais semelhantes existem em cada cultura, mas devido aos diferentes contextos, os meios de expressão e os mecanismos pelos quais vão passar serão diferentes. Por isso há a variedade mundial de fenômenos materiais, que variam em escala, conteúdo e atribuições simbólicas.

A existência da cultura material é universal, mas seu uso, estilo, forma, substância e atribuições simbólicas são culturalmente relativos (Yentsch \& Beaudry,2001:218).

Durante a década de 1990 novas abordagens foram oferecidas em relação às teorias da cultura material. O enfoque passou a ser o dos mercados e da comoditização, considerando-se os grupos minoritários como agentes ativos da sociedade, incluindo-se também análises sobre interação social e sistemas de crenças. Os objetos então não ganham qualidades exclusivamente por seu valor econômico e sim pelo que estes representam (valor simbólico).

As perguntas a serem feitas hoje, então, seriam: por que alguns objetos são importantes? Por que algumas relações entre objetos e pessoas são importantes e outras não? (Miller, 1984; Mullins, 1996,1999).

Outro enfoque é o da análise doméstica e vozes ativas. Este enfoque torna possível interpretar os padrões de comportamento dos consumidores ao opor o consumo individual e consumo corporativo e ao analisar os padrões de consumo (por exemplo, Beaudry et al, 1991; Hall, 1991; Yentsch,1994).

No fim da década de 1990 já estava claro que a idade, o gênero, a etnia, a religião, as crenças e a raça convergem na mente para criar expressivas formas pelas quais os indivíduos afirmam sua identidade social, e que cada um destes 
fatores são representados na forma de cultura material. Ou seja, os mesmos objetos podem ter usos diferentes em diferentes contextos e que o uso simbólico não pode ser deixado de lado ao se analisar um objeto.

Toda essa riqueza de possibilidades enfrenta, contudo, o "texto-centrismo" vigente em nossa sociedade e, consequentemente, em nossa educação e nos estudos educacionais que ela promove ${ }^{13}$. Um dos frutos esperados do presente trabalho é contribuir para que se perceba a necessidade de alterar-se tal quadro.

\section{Cultura material e História}

Historiadores da cultura material têm apontado, nos últimos anos, para a ausência de uma definição histórica dos problemas da cultura material (assim como sua correta inserção nos procedimentos que tentam descobrir e resolver os problemas da historiografia) por parte dos historiadores (Meneses 1983 e 1994; Rede, 1996).

Um dos problemas básicos diz respeito ao fato da expressão cultura material ser polissêmica e, portanto, como nota Rede (1996) passível de dar margem a ambigüidades. De fato essa ambigüidade deriva do fato do termo cultura material indicar tanto o objeto de estudo como uma forma de conhecimento. Em seu ensaio sobre as recentes tendências da historiografia nos estudos de cultura material, ele aponta diversos caminhos utilizados por especialistas (não somente historiadores) nos estudos com cultura material. São destacados os trabalhos que relacionam cultura material com universo social, comportamento e a psicologia, concluindo que os estudos sobre cultura material mantêm-se atrelados a campos e interesses particulares, e que essa compartimentação é responsável por perdurarem noções de cultura que não oferecem um lugar adequado à cultura material.

O grande problema consiste em não se reconhecer a cultura material como matriz e vetor de relações sociais, o que acarreta uma sub-avaliação de seu papel

\footnotetext{
${ }^{13}$ A Escola Nova(a partir de 1932) tinha preocupações com a Cultura Material que não sobreviveram além dos anos 50 (Sussekind de Mendonça, 1946). Apesar disso, o texto sempre imperou (Brandão, 1999) e continua imperando entre nós (Morin,E.,1999; Veiga \& Faria Filho, 2001).
} 
social e, consequentemente, seu uso como documento histórico. É possível que, exatamente, na área de estudos da cultura material se verifiquem os maiores impulsos a reconhecer nos objetos qualidades imanentes que eles, efetivamente, não podem ter. Meneses (1994) apresenta alguns princípios que deveriam nortear as preocupações dos historiadores em termos de documentos em geral e, mais especificamente, aqueles de cultura material:

"O que faz de um objeto documento não é, pois, uma carga latente, definida, de informação que ele encerre, pronta para ser extraída, como o sumo de um limão. O documento não tem em si sua própria identidade provisoriamente intransponível, até que o ósculo metodológico do historiador resgate a bela adormecida de seu sonho pragmático. É, pois, a questão de conhecimento que cria o sistema documental. O historiador não faz o documento falar: é o historiador quem fala e a explicitação de seus critérios e procedimentos é fundamental para definir o alcance de sua fala. Toda operação com documentos, portanto, é de natureza retórica".

(Meneses, 1994:21).

Assim sendo, a transferência, aos objetos, de qualidades do universo orgânico, como nota Rede (1996) constitui-se em uma espécie de fetichismo.

A cultura material só apresenta propriedades imanentes de natureza físicoquímica como matéria-prima, textura, forma, etc. Todos os demais atributos são impostos à documentação material. Isto é, os valores atribuídos à cultura material não dizem respeito à cultura material e sim à sociedade que os atribui.

Sendo esta é, portanto, a principal vertente a ser seguida em um estudo histórico que considerasse a cultura material como documento, ela também servirá como principal plataforma para a análise da amostragem de Livros Didáticos selecionada como corpo documental da presente dissertação. 


\section{Imagem e ilustração no livro didático brasileiro}

Em relação ao livro didático já foi dito (vide acima, p.34) que o Programa Nacional do Livro Didático -- PNLD --, apresenta como característica a avaliação dos livros que pretendem fazer parte do programa. Essa avaliação tem por objetivo excluir aqueles livros que, por diversas razões, não cumpram as diretrizes apontadas pelo MEC.

Alguns quesitos de exclusão estão ligados ao conteúdo do livro. Livros que apresentam racismo, formação de estereótipos, anacronismos, doutrinação religiosa, entre outras características consideráveis inaceitáveis, são excluídos.

Não são todas as falhas do livro que levam à exclusão. Por exemplo, o quesito "apresenta e discute as fontes históricas", absolutamente vital para o estudo da história e, também, da cultura material não está entre aqueles cuja ausência sirva para excluir uma obra. Como já foi apontado (vide acima p.22), os historiadores em geral não percebem a questão da cultura material como fonte de conhecimento histórico.

Um outro âmbito de considerações refere-se à utilização de imagens como fonte histórica, uma vertente de documentação ainda igualmente restrita e equivocada na prática de ensino de história. A imagem é sempre um segmento da cultura material, embora se constitua em campo de análise específico ${ }^{14}$ e em vias de expansão, com o recente lançamento, por estudiosos liderados por professores das Universidades de Londres e de Oxford, entre outras, do periódico Journal of Visual Culture $^{15}$, com seu primeiro volume publicado em abril de 2002.

Desde meados do século XIX os livros didáticos de história já apresentavam ilustrações, mas foi em torno de 1960 que elas tiveram sua importância aumentada nesse tipo de veículo, assumindo o papel de torná-los mais atraentes e agradáveis aos olhos de alunos e professores (o volume de História dos PCNs também é amplamente ilustrado). Essa questão já foi abordada por Lins (1977), que denominou

\footnotetext{
${ }^{14}$ A este respeito, a obra de N. Bryson,M.Holley \& K.Moxey(eds.), Visual Culture (1994), deve servirnos como parâmetro orientador.

${ }^{15}$ Journal of Visual Culture, vol.1, $\mathrm{n}^{\circ} .1$, abril 2002, Sage Publications, Londres.
} 
esse aumento das imagens, de uso lúdico, nos livros didáticos, de "Disneylândia pedagógica".

O Guia de livros didáticos de 2001 aponta que "a presença de boas ilustrações constitui-se em motivação essencial para o bom uso do livro, observando se estas estão isentas de estereótipos, acompanhadas de legenda e crédito, se são adequadas ao assunto, integradas ao texto, se auxiliam a compreensão e recorrem a diferentes linguagens visuais" (MEC 2000).

Esse comentário deixa claro que, também para os especialistas do PNLD da área de História, as imagens são apenas complementos do texto escrito, que como já foi dito, é uma das principais posturas dos historiadores em relação às imagens e à cultura material.

Essa visão é também compartilhada pelos especialistas em livro didático como é o caso de Bittencourt (1997), que tenta mostrar se as imagens "cumprem seu papel" (que para a autora seria o de complementar os textos do livro) ou servem apenas como ilustrações que visam tornar as páginas mais atrativas para os jovens leitores.

Ou seja, nem quando se combate a imagem como simples elemento lúdico, o que se coloca no lugar é o uso da imagem como mera ilustração do texto.

Como já foi dito acima (vide p.18), a maioria dos estudos acadêmicos brasileiros relacionados ao livro didático caracterizam-se pela análise do conteúdo informativo dos livros.

As análises dos livros didáticos, independentemente de suas problemáticas, por razões que dizem respeito à formação de pesquisadores e à carência de instrumentos apropriados, ficam tradicionalmente restritas à análise de texto.

Esse privilégio conferido à análise textual se solidificou pelo desenvolvimento de métodos e instrumentos de análise lingüísticas, destacando-se a lexicométrica (CHOPPIN 2004). Apenas a partir dos anos 1980, com o impulso da história das mentalidades, é que o livro didático deixou de ser considerado um livro-texto que apresentava algumas ilustrações com finalidade estética e passou a se levar em conta a articulação semântica que une o texto e a imagem. 
Embora existam alguns estudos sobre o uso de imagens nos livros didáticos, com destaque para os estudos franceses, que buscam ver, neles, o papel das imagens na formação de uma memória histórica, enfatizando os aspectos ideológico das ilustrações (Amalvi,1988), estes estudos são praticamente ignorados pelas obras congêneres brasileiras.

A importância do uso das imagens como recurso pedagógico tem, de fato, sido destacada há muito tempo e, no caso específico da História, sugeria-se que as imagens fossem usadas para que os alunos pudessem "ver as cenas históricas" e dessa maneira concretizar a noção abstrata de "tempo histórico" (Lavisse, 1887). Os defensores desse uso se esquecem que as imagens não são a realidade e tampouco seu "reflexo", mas representações que passam por diversos filtros culturais, sendo seu autor um dos principais.

Outra questão importante em relação às imagens e seu uso em livros didáticos é o fato que, por ser uma mercadoria, o livro didático está à mercê das leis de mercado. As questões técnicas de fabricação e o custo da edição delimitam os critérios de organização e uso das ilustrações. Para diminuir os gastos com direitos autorais, por exemplo, os editores contratam desenhistas para reproduzir quadros ou gravuras originais. A diagramação e a paginação do livro não são funções do autor e hoje existem até especialistas em pesquisa iconográfica que acabam escolhendo as ilustrações no lugar dos autores, corroborando definitivamente que os próprios autores desvinculam o texto das imagens. 


\section{CAPÍTULO II - MATERIAL UTILIZADO E TABULAÇÃO DOS DADOS}

Como já foi dito acima (vide p. 18) uma parte consistente dos estudos acadêmicos sobre o Livro Didático é de difícil utilização e de escasso benefício, em função de amostragens sem critério. Para não cometer os mesmos erros apontados acima e para que o presente trabalho possa produzir sentido, escolhemos como corpo documental todos os livros de História aprovados pelo PNLD 2003 -- ano em que iniciamos os trabalhos para essa dissertação -- com conteúdo de História Antiga, em um total de 15 coleções:

\section{Elenco dos livros usados:}

PILETTI, C;PILETTI, N. História e Vida Integrada, Ed. Ática. MONTELLATO, A; CABRINI, C; CATELLI JUNIOR, R. História Temática, Ed. Scipione. MACEDO, J; OLIVEIRA, M. Uma História em Construção. Ed. do Brasil. VALENTINI, L; VILELA, M; ORDOÑEZ, M. Cultura e Sociedade.Ed. IBEP. ORDOÑEZ, M. História. Ed. IBEP. FURTADO, J; VILLA; M. História Geral. Ed. Moderna COUTO, E; CARMO, S. História Passado e Presente. Ed. Saraiva/Atual. TOLEDO, E; DREGUER, R. História Cotidiano e Mentalidades.Ed. Saraiva/Atual. MARTINS, J. História - Edição Reformulada. Ed. FTD MARQUES, A; BERUTTI, F; FARIA, R. História e Companhia. Ed. Lê DUARTE, G. Jornada para o nosso tempo. Ed. Lê. ALVES, K; MOURA,R; BELISÁRIO, G. Nas trilhas da História. Ed. Dimensão. SCHIMIDT, M. Nova História crítica. Ed. Nova Geração MOCELLIN,R. Para compreender a História. Ed. do Brasil ANTUNES, M; MARANHÃO, R. Trabalho e civilização - Uma História Global. Ed. Moderna.

\section{Quadro de categoriais de análise}

Criamos um banco de dados contendo todas as imagens contidas nos livros didáticos que compõem nosso corpo documental. Nesse banco de dados, as 
imagens foram divididas em categorias, a partir do meio (pintura a óleo, gravura, têmpera, aquarela, escultura, estruturas urbanas e rurais...) e o suporte (tela, mural, papel...) das imagens.

Partiu-se de três categorias principais: vestígios arqueológicos, representações futuras e fotos. Cada uma dessas categorias contém uma série de subcategorias que, por sua vez, também podem conter novas categorias, formando um organograma. Estabelecemos 54 categoriais e o quadro obtido embasou nossas considerações

O maior desafio em criar esse banco de dados foi exatamente essa categorização das imagens. A maioria absoluta dos livros não especifica qual o meio ou o suporte das imagens apresentadas. Outras informações sobre as imagens também são raras, como, por exemplo, o lugar onde foram encontrados os objetos (no caso dos vestígios arqueológicos). Soma-se a isso o fato de que a maioria das imagens apresentadas nos livros é apenas um detalhe de uma imagem maior, tornando às vezes quase impossível sua categorização.

O quadro adotou o critério de descritores nomeados a partir das iniciais de cada categoria:

Pintura = P e P1, P2, P3 etc. em função das sub-categorias.

As categorias de análise são: 


\begin{tabular}{|c|c|c|c|c|c|}
\hline $\begin{array}{l}\text { Pinturas } \\
\text { ICódigo }\end{array}$ & $\begin{array}{c}\text { Estruturas } \\
\text { Urbanas e } \\
\text { Rurais/Código }\end{array}$ & $\begin{array}{c}\text { Registros } \\
\text { Escritos/Código }\end{array}$ & $\begin{array}{l}\text { Utensílios } \\
\text { /Código }\end{array}$ & $\begin{array}{l}\text { Orgânico } \\
\text { ICódigo }\end{array}$ & $\begin{array}{l}\text { Diversos } \\
\text { /Código }\end{array}$ \\
\hline $\begin{array}{l}\text { Rupestre - } \\
\text { P1 }\end{array}$ & Templos - EUR1 & Estela - RE1 & $\begin{array}{l}\text { Ferramentas } \\
-\mathrm{U} 1\end{array}$ & $\begin{array}{l}\text { Humanos } \\
-\mathrm{O} 1\end{array}$ & $\begin{array}{l}\text { Meios de } \\
\text { Transporte } \\
\text { - MT }\end{array}$ \\
\hline Mural - P2 & Pontes - EUR2 & $\begin{array}{c}\text { Tabuletas } \\
\text { Cuneiformes - } \\
\text { RE2 }\end{array}$ & Mobília - U2 & $\begin{array}{l}\text { Fauna- } \\
\text { O2 }\end{array}$ & $\begin{array}{c}\text { Tapeçaria - } \\
\text { T }\end{array}$ \\
\hline $\begin{array}{c}\text { Em } \\
\text { madeira - } \\
\text { P3 }\end{array}$ & Palácios - EUR3 & Mural - RE3 & Armas - U3 & Flora - O3 & $\begin{array}{c}\text { Gravura - } \\
\text { G }\end{array}$ \\
\hline $\begin{array}{l}\text { Em vaso - } \\
\text { P4 }\end{array}$ & Arcos - EUR4 & Papel - RE4 & Moedas - U4 & $\begin{array}{l}\text { Múmia - } \\
\text { O4 }\end{array}$ & $\begin{array}{c}\text { Esculturas } \\
-E \\
-E 1 \\
\text { Plena-E2 } \\
\end{array}$ \\
\hline $\begin{array}{c}\text { Em vaso } \\
\text { - figuras } \\
\text { vermelhas - } \\
\text { P4.1 }\end{array}$ & Teatros - EUR5 & Bronze - RE5 & $\begin{array}{l}\text { Vestimentas - } \\
\text { U5 }\end{array}$ & & $\begin{array}{c}\text { Mosaicos - } \\
\text { M }\end{array}$ \\
\hline $\begin{array}{c}\text { Em vaso - } \\
\text { figuras } \\
\text { negras - } \\
\text { P4.2 }\end{array}$ & $\begin{array}{l}\text { Ruas/estradas - } \\
\text { EUR6 }\end{array}$ & & $\begin{array}{l}\text { Instrumentos } \\
\text { Musicais - U6 }\end{array}$ & & $\begin{array}{l}\text { Desenho - } \\
\text { D }\end{array}$ \\
\hline $\begin{array}{l}\text { Em azulejo } \\
\quad-\text { P5 }\end{array}$ & Aquedutos - EUR7 & & $\begin{array}{c}\text { Artefatos de } \\
\text { pedra lascada } \\
\text { - U7 }\end{array}$ & & \\
\hline $\begin{array}{l}\text { Em tela - } \\
\text { P6 }\end{array}$ & Muralhas - EUR8 & & $\begin{array}{c}\text { Recipientes - } \\
\text { U8 }\end{array}$ & & \\
\hline Óleo - P6.1 & Estádios - EUR9 & & & & \\
\hline $\begin{array}{l}\text { Têmpera - } \\
\text { P6.2 }\end{array}$ & Torres - EUR10 & & & & \\
\hline $\begin{array}{l}\text { Em livro - } \\
\text { P7 }\end{array}$ & $\begin{array}{c}\text { Cidades/Vilas - } \\
\text { EUR11 }\end{array}$ & & & & \\
\hline $\begin{array}{l}\text { Papiro - } \\
\text { P7.1 }\end{array}$ & $\begin{array}{c}\text { Pirâmides/Zigurates - } \\
\text { EUR12 }\end{array}$ & & & & \\
\hline \multirow[t]{8}{*}{$\begin{array}{l}\text { Papel - } \\
\text { P7.2 }\end{array}$} & Termas - EUR13 & & & & \\
\hline & Sambaquis - EUR14 & & & & \\
\hline & Casas - EUR15 & & & & \\
\hline & Sepulturas - EUR16 & & & & \\
\hline & Bibliotecas - EUR17 & & & & \\
\hline & Escadarias - EUR18 & & & & \\
\hline & Colunas - EUR19 & & & & \\
\hline & Fórum - EUR20 & & & & \\
\hline
\end{tabular}




\section{Quadro 2 - Codificação das Mediações Interpretativas}

\begin{tabular}{|l|l|}
\hline Tipo & Código \\
\hline Desenhos Atuais & Ml1 \\
\hline Pinturas & MI2 \\
\hline Reconstruções & MI3 \\
\hline Manequim & MI3.1 \\
\hline Maquetes & Ml3.2 \\
\hline Tamanho natural & Ml3.3 \\
\hline Planta & Ml3.4 \\
\hline Esculturas & $\mathrm{R} 4$ \\
\hline
\end{tabular}

\section{Quadro 3 - Codificação das Fotos}

\begin{tabular}{|l|l|}
\hline Tipo & Código \\
\hline $\begin{array}{l}\text { Elementos de Cultura Material } \\
\text { antigos em uso }\end{array}$ & $\mathrm{F} 1$ \\
\hline $\begin{array}{l}\text { Elementos de Cultura Material } \\
\text { modernos em uso }\end{array}$ & $\mathrm{F} 2$ \\
\hline Personalidades & $\mathrm{F} 3$ \\
\hline Conceitos & $\mathrm{F} 4$ \\
\hline
\end{tabular}

\section{Tabulação dos dados}

Após a criação do banco de dados contendo as imagens apresentadas nos livros estudados, fizemos a tabulação desses dados.

Agrupando-se as imagens em função das culturas a que pertencem montamos as tabelas abaixo, contendo a categoria das imagens, a quantidade de imagens dessa categoria, número de repetições dessas imagens, a porcentagem dessa categoria em relação ao total de imagens dessa determinada cultura, a quantidades de livros em que essa categoria aparece e a porcentagem dos livros em que essa categoria aparece em relação ao total de livros em que essa cultura aparece. 
Tabela 1 - Categorização das imagens referentes aos Mesopotâmicos

\begin{tabular}{|c|c|c|c|c|c|}
\hline \multicolumn{4}{|c|}{ Quantidade de Imagens - 148 (100\%) } & \multicolumn{2}{|c|}{$\begin{array}{l}\text { Quantidade de livros }-14 \\
(100 \%)\end{array}$} \\
\hline Categoria & $\begin{array}{l}\text { Quantidade } \\
\text { de Imagens }\end{array}$ & Repetições & $\%$ & $\begin{array}{l}\text { Quantidade } \\
\text { de Livros }\end{array}$ & $\begin{array}{l}\text { \% livros com } \\
\text { a imagem }\end{array}$ \\
\hline E2 & 21 & 4 & 17 & 10 & 71 \\
\hline MI1 & 23 & 0 & 17 & 10 & 71 \\
\hline$\overline{E 1}$ & 19 & 2 & 14 & 14 & 100 \\
\hline RE2 & 16 & 3 & 12 & 14 & 100 \\
\hline RE1 & 3 & 10 & 8 & 11 & 78 \\
\hline$M$ & 3 & 9 & 8 & 10 & 71 \\
\hline EUR12 & 6 & 0 & 4.5 & 5 & 35 \\
\hline MI3.3 & 5 & 0 & 3 & 4 & 28 \\
\hline $\mathrm{P} 2$ & 4 & 0 & 3 & 3 & 21 \\
\hline EUR1 & 3 & 0 & 2 & 3 & 21 \\
\hline EUR11 & 3 & 0 & 2 & 3 & 21 \\
\hline LP2 & 2 & 0 & 1 & 2 & 14 \\
\hline EUR15 & 1 & 0 & 0 & 1 & 7 \\
\hline EUR3 & 1 & 0 & 0 & 1 & 7 \\
\hline $\mathrm{F} 1$ & 1 & 0 & 0 & 1 & 7 \\
\hline $\mathrm{MI3.4}$ & 1 & 0 & 0 & 1 & 7 \\
\hline U6 & 1 & 0 & 0 & 1 & 7 \\
\hline
\end{tabular}


Tabela 2 - Categorização das imagens referentes aos Egípcios

\begin{tabular}{|l|l|l|l|l|l|}
\hline \multicolumn{3}{|c|}{$\begin{array}{l}\text { Quantidade de imagens - 248 } \\
(100 \%)\end{array}$} & \multicolumn{2}{l|}{$\begin{array}{l}\text { Quantidade de livros - 15 } \\
(100 \%)\end{array}$} \\
\hline Categoria & $\begin{array}{l}\text { Quantidade } \\
\text { de imagens }\end{array}$ & Repetições & $\%$ & $\begin{array}{l}\text { Quantidade } \\
\text { de livros }\end{array}$ & $\begin{array}{l}\text { \% livros com } \\
\text { imagem }\end{array}$ \\
\hline P2 & 35 & 11 & 19 & 13 & 87 \\
\hline MI1 & 40 & 0 & 16 & 13 & 87 \\
\hline E2 & 30 & 5 & 14 & 12 & 80 \\
\hline EUR12 & 19 & 2 & 8 & 14 & 93 \\
\hline E1 & 14 & 1 & 6 & 8 & 53 \\
\hline EUR1 & 12 & 0 & 5 & 7 & 47 \\
\hline U5 & 9 & 2 & 4 & 9 & 60 \\
\hline P7.1 & 8 & 2 & 4 & 8 & 53 \\
\hline O4 & 5 & 3 & 3 & 6 & 40 \\
\hline RE3 & 7 & 1 & 3 & 7 & 47 \\
\hline U2 & 5 & 1 & 2 & 4 & 27 \\
\hline F1 & 4 & 1 & 2 & 2 & 13 \\
\hline MT & 3 & 0 & 1 & 3 & 20 \\
\hline F3 & 2 & 0 & 1 & 2 & 13 \\
\hline U8 & 2 & 0 & 1 & 2 & 13 \\
\hline D & 1 & 0 & 0.45 & 1 & 6 \\
\hline EUR16 & 1 & 0 & 0.45 & 1 & 6 \\
\hline M12 & 1 & 0 & 0.45 & 1 & 6 \\
\hline U6 & 1 & 0 & 0.45 & 1 & 6 \\
\hline
\end{tabular}


Tabela 3 - Categorização das imagens referentes aos Persas

\begin{tabular}{|c|c|c|c|c|c|}
\hline \multicolumn{4}{|c|}{ Quantidade de imagens - 51 (100\%) } & \multicolumn{2}{|c|}{$\begin{array}{l}\text { Quantidade de livros - } 12 \\
(100 \%)\end{array}$} \\
\hline Categoria & $\begin{array}{l}\text { Quantidade } \\
\text { de Imagens }\end{array}$ & Repetições & $\%$ & $\begin{array}{l}\text { Quantidade } \\
\text { de Livros }\end{array}$ & $\begin{array}{lr}\% & \text { livros } \\
\text { com } & a \\
\text { imagem }\end{array}$ \\
\hline E1 & 9 & 1 & 20 & 5 & 42 \\
\hline EUR3 & 5 & 1 & 12 & 5 & 42 \\
\hline MI1 & 6 & 0 & 12 & 4 & 33 \\
\hline E2 & 5 & 0 & 10 & 3 & 25 \\
\hline U5 & 3 & 1 & 8 & 4 & 33 \\
\hline U4 & 2 & 1 & 6 & 3 & 25 \\
\hline EUR11 & 2 & 0 & 4 & 2 & 17 \\
\hline EUR28 & 2 & 0 & 4 & 2 & 17 \\
\hline F2 & 2 & 0 & 4 & 2 & 17 \\
\hline U8 & 1 & 1 & 4 & 2 & 17 \\
\hline EUR & 1 & 0 & 2 & 1 & 8 \\
\hline EUR16 & 1 & 0 & 2 & 1 & 8 \\
\hline $\mathrm{F}$ & 1 & 0 & 2 & 1 & 8 \\
\hline $\mathrm{P} 2$ & 1 & 0 & 2 & 1 & 8 \\
\hline $\mathrm{P} 4.1$ & 1 & 0 & 2 & 1 & 8 \\
\hline $\bar{U}$ & 1 & 0 & 2 & 1 & 8 \\
\hline
\end{tabular}


Tabela 4 - Categorização das imagens referentes aos Hebreus

\begin{tabular}{|c|c|c|c|c|c|}
\hline \multicolumn{4}{|c|}{ Quantidade de imagens - 48 (100\%) } & \multicolumn{2}{|c|}{$\begin{array}{l}\text { Quantidade de livros }-12 \\
(100 \%)\end{array}$} \\
\hline Categoria & $\begin{array}{l}\text { Quantidade } \\
\text { de Imagens }\end{array}$ & Repetições & $\%$ & $\begin{array}{l}\text { Quantidade } \\
\text { de Livros }\end{array}$ & $\begin{array}{l}\text { \% livros com a } \\
\text { imagem }\end{array}$ \\
\hline MI1 & 6 & 0 & 12 & 3 & 25 \\
\hline EUR11 & 4 & 2 & 12 & 6 & 50 \\
\hline EUR8 & 4 & 0 & 8 & 4 & 33 \\
\hline E2 & 3 & 0 & 6 & 3 & 25 \\
\hline EUR1 & 3 & 0 & 6 & 3 & 25 \\
\hline RE4 & 3 & 0 & 6 & 3 & 25 \\
\hline $\mathrm{F} 2$ & 3 & 0 & 6 & 1 & 8 \\
\hline MI3.3 & 2 & 1 & 6 & 3 & 25 \\
\hline EUR10 & 2 & 0 & 4 & 2 & 17 \\
\hline $\mathrm{F}$ & 2 & 0 & 4 & 1 & 8 \\
\hline $\mathrm{D}$ & 1 & 0 & 2 & 1 & 8 \\
\hline E1 & 1 & 0 & 2 & 1 & 8 \\
\hline P7.2 & 1 & 0 & 2 & 1 & 8 \\
\hline $\mathrm{MI2}$ & 1 & 0 & 2 & 1 & 8 \\
\hline U1 & 1 & 0 & 2 & 1 & 8 \\
\hline U8 & 1 & 0 & 2 & 1 & 8 \\
\hline
\end{tabular}


Tabela 5 - Categorização das imagens referentes aos Fenícios e Cretenses

\begin{tabular}{|c|c|c|c|c|c|}
\hline \multicolumn{4}{|c|}{ Quantidade de imagens - 52 (100\%) } & \multicolumn{2}{|c|}{$\begin{array}{l}\text { Quantidade de livros - } 12 \\
(100 \%)\end{array}$} \\
\hline Categoria & $\begin{array}{l}\text { Quantidade } \\
\text { de Imagens }\end{array}$ & Repetições & $\%$ & $\begin{array}{l}\text { Quantidade } \\
\text { de Livros }\end{array}$ & $\begin{array}{l}\text { \% livros com a } \\
\text { imagem }\end{array}$ \\
\hline U8 & 8 & 1 & 17 & 5 & 42 \\
\hline E1 & 5 & 1 & 11 & 6 & 50 \\
\hline E2 & 6 & 0 & 11 & 5 & 42 \\
\hline MI1 & 6 & 0 & 11 & 4 & 33 \\
\hline EUR3 & 5 & 0 & 9 & 3 & 25 \\
\hline $\mathrm{P} 2$ & 3 & 2 & 9 & 4 & 33 \\
\hline U5 & 2 & 2 & 7 & 3 & 25 \\
\hline EUR11 & 2 & 0 & 3 & 2 & 17 \\
\hline MI3.3 & 2 & 0 & 3 & 2 & 17 \\
\hline EUR & 1 & 0 & 1 & 1 & 8 \\
\hline EUR15 & 1 & 0 & 1 & 1 & 8 \\
\hline $\mathrm{F}$ & 1 & 0 & 1 & 1 & 8 \\
\hline$P$ & 1 & 0 & 1 & 1 & 8 \\
\hline P4.2 & 1 & 0 & 1 & 1 & 8 \\
\hline $\mathrm{RE}$ & 1 & 0 & 1 & 1 & 8 \\
\hline U1 & 1 & 0 & 1 & 1 & 8 \\
\hline
\end{tabular}


Tabela 6 - Categorização das imagens referentes à China e Índia

\begin{tabular}{|c|c|c|c|c|c|}
\hline \multicolumn{4}{|c|}{ Quantidade de imagens - 105 (100\%) } & \multicolumn{2}{|c|}{$\begin{array}{l}\text { Quantidade de livros } 12 \\
(100 \%)\end{array}$} \\
\hline Categoria & $\begin{array}{l}\text { Quantidade } \\
\text { de Imagens }\end{array}$ & Repetições & $\%$ & $\begin{array}{l}\text { Quantidade } \\
\text { de Livros }\end{array}$ & $\begin{array}{l}\% \text { livros com } \\
\text { a imagem }\end{array}$ \\
\hline E2 & 21 & 2 & 22 & 12 & 100 \\
\hline MI1 & 21 & 0 & 20 & 6 & 50 \\
\hline$P$ & 19 & 0 & 18 & 7 & 60 \\
\hline $\mathrm{F} 2$ & 8 & 1 & 8.5 & 4 & 30 \\
\hline EUR8 & 5 & 0 & 5 & 5 & 41 \\
\hline $\mathrm{G}$ & 4 & 0 & 4 & 2 & 16 \\
\hline U8 & 4 & 0 & 4 & 3 & 25 \\
\hline E1 & 3 & 0 & 3 & 2 & 16 \\
\hline EUR1 & 3 & 0 & 3 & 2 & 16 \\
\hline RE4 & 3 & 0 & 3 & 3 & 25 \\
\hline U1 & 3 & 0 & 3 & 3 & 25 \\
\hline$B$ & 1 & 0 & 1 & 1 & 8 \\
\hline $\mathrm{D}$ & 1 & 0 & 1 & 1 & 8 \\
\hline EUR & 1 & 0 & 1 & 1 & 8 \\
\hline EUR11 & 1 & 0 & 1 & 1 & 8 \\
\hline EUR15 & 1 & 0 & 1 & 1 & 8 \\
\hline $\mathrm{RE}$ & 1 & 0 & 1 & 1 & 8 \\
\hline $\mathrm{F} 1$ & 1 & 0 & 1 & 1 & 8 \\
\hline
\end{tabular}


Tabela 7 - Categorização das imagens referentes aos Gregos

\begin{tabular}{|c|c|c|c|c|c|}
\hline \multicolumn{4}{|c|}{ Quantidade de imagens - 376 (100\%) } & \multicolumn{2}{|c|}{$\begin{array}{l}\text { Quantidade de livros - } 15 \\
(100 \%)\end{array}$} \\
\hline Categoria & $\begin{array}{l}\text { Quantidade } \\
\text { de Imagens }\end{array}$ & Repetições & $\%$ & $\begin{array}{l}\text { Quantidade } \\
\text { de Livros }\end{array}$ & $\begin{array}{l}\% \text { livros com a } \\
\text { imagem }\end{array}$ \\
\hline E2 & 69 & 21 & 24 & 15 & 100 \\
\hline P4.1 & 31 & 6 & 10 & 12 & 80 \\
\hline U8 & 29 & 8 & 10 & 12 & 80 \\
\hline MI1 & 36 & 0 & 10 & 12 & 80 \\
\hline EUR1 & 31 & 1 & 8.5 & 12 & 80 \\
\hline P4.2 & 20 & 7 & 7 & 11 & 73 \\
\hline E1 & 17 & 4 & 5 & 11 & 73 \\
\hline EUR5 & 11 & 1 & 3 & 12 & 80 \\
\hline $\mathrm{M}$ & 5 & 7 & 3 & 7 & 47 \\
\hline EUR11 & 10 & 1 & 3 & 11 & 73 \\
\hline $\mathrm{MI} 2$ & 4 & 3 & 2 & 5 & 33 \\
\hline U5 & 5 & 0 & 1 & 4 & 26 \\
\hline $\mathrm{D}$ & 4 & 0 & 1 & 2 & 13 \\
\hline R3.3 & 3 & 0 & 1 & 2 & 13 \\
\hline F1 & 2 & 0 & 1 & 1 & 6 \\
\hline $\mathrm{P}$ & 2 & 0 & 1 & 2 & 13 \\
\hline U1 & 2 & 0 & 1 & 2 & 13 \\
\hline EUR10 & 1 & $\mathrm{O}$ & 0 & 1 & 6 \\
\hline F2 & 1 & $\mathrm{O}$ & 0 & 1 & 6 \\
\hline EUR17 & 1 & $\mathrm{O}$ & 0 & 1 & 6 \\
\hline EUR18 & 1 & $\mathrm{O}$ & 0 & 1 & 6 \\
\hline $\mathrm{G}$ & 1 & $\mathrm{O}$ & 0 & 1 & 6 \\
\hline MT & 1 & $\mathrm{O}$ & 0 & 1 & 6 \\
\hline $\mathrm{Ml} 2$ & 1 & $\mathrm{O}$ & 0 & 1 & 6 \\
\hline P3 & 1 & $\mathrm{O}$ & 0 & 1 & 6 \\
\hline MI3.4 & 1 & $\mathrm{O}$ & 0 & 1 & 6 \\
\hline RE1 & 1 & $\mathrm{O}$ & 0 & 1 & 6 \\
\hline U3 & 1 & $\mathrm{O}$ & 0 & 1 & 6 \\
\hline U4 & 1 & 0 & 0 & 1 & 6 \\
\hline
\end{tabular}


Tabela 8 - Categorização das imagens referentes aos Romanos

\begin{tabular}{|c|c|c|c|c|c|}
\hline \multicolumn{4}{|c|}{ Quantidade de imagens - 439 (100\%) } & \multicolumn{2}{|c|}{$\begin{array}{l}\text { Quantidade de livros - } 15 \\
(100 \%)\end{array}$} \\
\hline Categoria & $\begin{array}{l}\text { Quantidade } \\
\text { de Imagens }\end{array}$ & Repetições & $\%$ & $\begin{array}{l}\text { Quantidade } \\
\text { de Livros }\end{array}$ & $\begin{array}{l}\text { \% livros com a } \\
\text { imagem }\end{array}$ \\
\hline E2 & 48 & 13 & 14 & 15 & 100 \\
\hline E1 & 48 & 3 & 11 & 15 & 100 \\
\hline MI1 & 50 & 0 & 11 & 15 & 100 \\
\hline $\mathrm{M}$ & 9 & 24 & 7.5 & 13 & 87 \\
\hline $\mathrm{P} 2$ & 19 & 4 & 5 & 10 & 67 \\
\hline EUR20 & 13 & 8 & 5 & 14 & 93 \\
\hline EUR7 & 14 & 0 & 3 & 11 & 73 \\
\hline EUR4 & 13 & 0 & 3 & 8 & 53 \\
\hline EUR9 & 13 & 0 & 3 & 10 & 67 \\
\hline EUR15 & 11 & 0 & 2.5 & 6 & 40 \\
\hline EUR11 & 9 & 0 & 2 & 6 & 40 \\
\hline $\mathrm{Ml} 2$ & 9 & 0 & 2 & 6 & 40 \\
\hline EUR1 & 8 & 0 & 2 & 6 & 40 \\
\hline LP3.2 & 5 & 3 & 2 & 4 & 26 \\
\hline EUR16 & 6 & 1 & 1.5 & 7 & 46 \\
\hline EUR & 6 & 0 & 1 & 5 & 31 \\
\hline U4 & 6 & 0 & 1 & 4 & 26 \\
\hline$P$ & 5 & 0 & 1 & 4 & 26 \\
\hline U3 & 5 & 0 & 1 & 3 & 20 \\
\hline U5 & 3 & 2 & 1 & 5 & 33 \\
\hline U8 & 5 & 0 & 1 & 4 & 26 \\
\hline EUR13 & 4 & 0 & 1 & 4 & 26 \\
\hline EUR5 & 4 & 0 & 1 & 2 & 13 \\
\hline EUR6 & 3 & 0 & 0.7 & 3 & 20 \\
\hline $\mathrm{O} 1$ & 3 & 0 & 0.7 & 2 & 13 \\
\hline P7.2 & 2 & 0 & 0.5 & 2 & 13 \\
\hline RE5 & 2 & 0 & 0.5 & 2 & 13 \\
\hline $\mathrm{U}$ & 2 & 0 & 0.5 & 2 & 13 \\
\hline EUR2 & 1 & 0 & 0.2 & 1 & 6 \\
\hline EUR8 & 1 & 0 & 0.2 & 1 & 6 \\
\hline P5 & 1 & 0 & 0.2 & 1 & 6 \\
\hline $\mathrm{MI3.4}$ & 1 & 0 & 0.2 & 1 & 6 \\
\hline $\mathrm{Ml4}$ & 1 & 0 & 0.2 & 1 & 6 \\
\hline
\end{tabular}


A tabulação dos dados nos permitiu quantificar as imagens e suas categorias de acordo com as civilizações que as produziram ou que são representadas nas mesmas, segundo o critério de escolha dos autores.

A partir dessa quantificação foi possível a montagem de quadros indicativos e, partindo deles, determinar as imagens, meios e suportes de maior presença, assim como as ausências, em cada civilização estudada.

São essas ausências e presenças que serão analisadas no próximo capítulo, com o objetivo de avaliar o uso que autores dos livros didáticos fazem da cultura material que seus livros apresentam ao leitor. 


\section{CAPITULO III. De uma impossível leitura de cultura material}

Baseando-nos nos quadros indicativos de ausências e presenças (vide capítulo III acima), buscamos discutir, no presente capítulo, a maneira como a cultura material é apresentada nos livros analisados, que problemas levanta para discussão e como enriquece o conteúdo que atais livros pretendem difundir.

\section{A Pré-História e a representação do documento.}

Com referência à pré-história, os livros apresentam um total de 254 imagens, portanto $16 \%$ do total de imagens usadas na amostragem. Esses 16\% se concretizam em 254 imagens que são apresentadas 281 vezes. Ou seja, essa diferença de 26 imagens equivalem a repetições (2 repetições de estátuas de Vênus paleolítica, uma repetição de pintura rupestre de Altamira, seis de pinturas rupestres de Lascaux, seis de pinturas rupestres da região do Saara, sete de pinturas rupestres de São Raimundo Nonato, uma de instrumentos pré-históricos, uma de moedor de grãos, uma de vaso de cerâmica, uma mediação interpretativa de uma caçada pré-histórica e uma mediação interpretativa de objetos pré-históricos). Estas repetições tanto aparecem no mesmo livro como em livros diferentes.

A categoria que mais aparece é a categoria MI1 (desenhos atuais) com 100 imagens (35\% das imagens do período pré-histórico) com apenas duas repetições (caçada pré-histórica e artefatos pré-históricos). Essa categoria aparece em 15 livros (100\% dos livros que tratam do período).

Este é um dado interessante, pois mesmo em um período da História onde não existia a escrita, a Cultura Material não é utilizada a contento. Como ira o aluno perceber as diferenças e particularidades dos diversos tipos de ferramentas e utensílios pré-históricos se ele somente tem acesso a uma representação precária dos mesmos?

A segunda categoria que mais aparece é a P1 (pintura rupestre). Ela aparece em 54 imagens ( $21 \%$ das imagens do período) com 74 presenças (uma repetição de pintura rupestre de Altamira, seis de pinturas rupestres de Lascaux, seis de pinturas 
rupestres da região do Saara, sete de pinturas rupestres de São Raimundo Nonato). Essa categoria também aparece em 100\% dos livros que tratam do período.

Destas 54 imagens, 61\% são de pinturas que se encontram fora do Brasil (Europa e região do Saara); $31 \%$ são de pinturas no Brasil e $7 \%$ não são identificadas. Ao olharmos mais detalhadamente estas localidades percebermos que existem duas localidades que se destacam pelo número de imagens delas originadas, uma no Brasil e outra na França. São oito imagens procedentes de Lascaux, na França, em 14 presenças (18\% de P1) que aparecem em 11 livros (73\% dos livros em que aparece a categoria). Já as pinturas rupestres de S. Raimundo Nonato, no Brasil, aparecem em 8 imagens e 15 presenças (20\% de P1) e aparecem em 8 livros (53\% dos livros que apresentam a categoria).

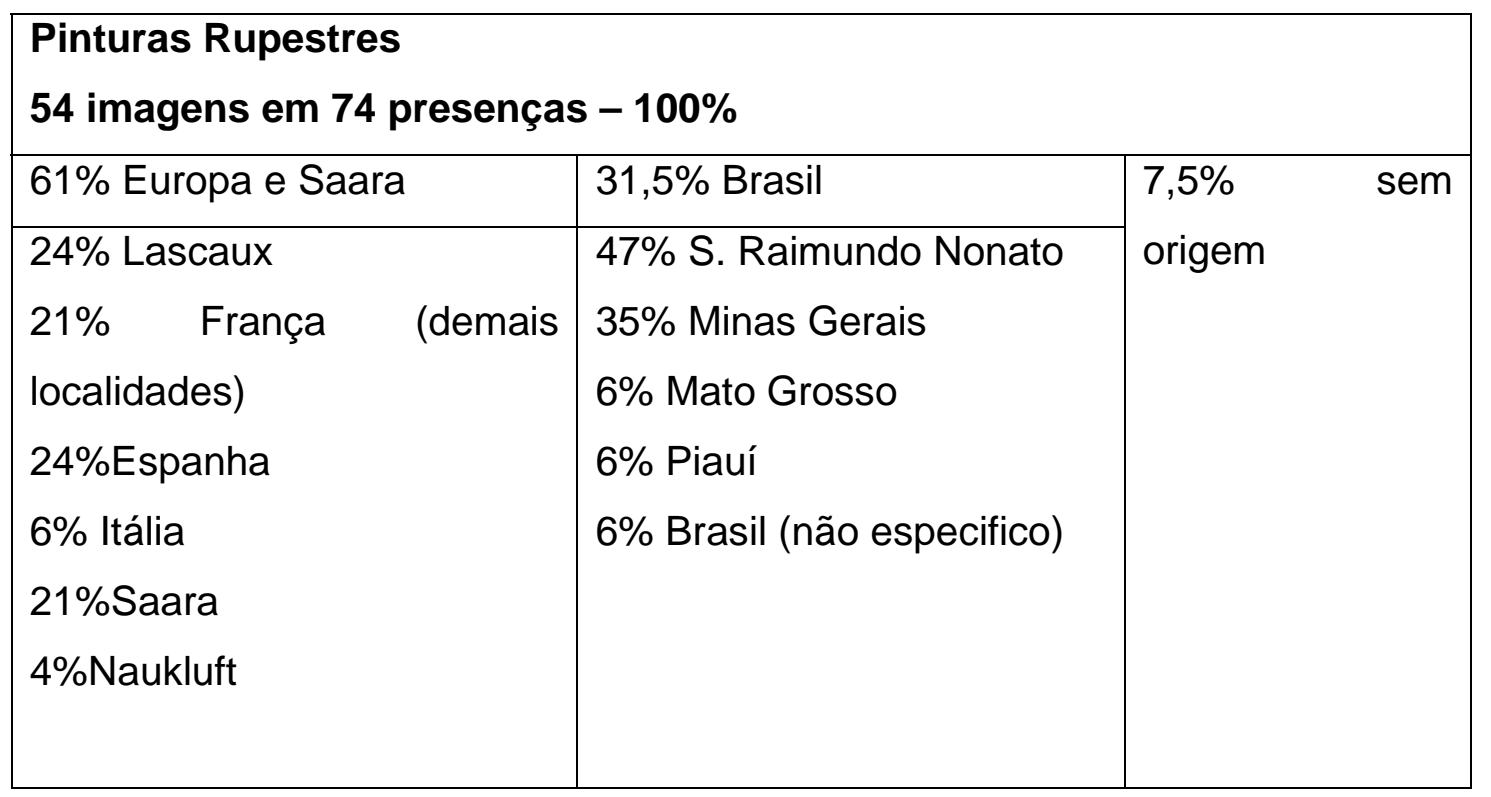

Nenhuma das imagens de pinturas rupestres apresenta as dimensões de tais pinturas.

Além disso, não é revelado se as pinturas foram feitas do lado de fora, na entrada ou nas profundezas das cavernas.

A ausência desses dados prejudica a compreensão do conjunto das pinturas rupestres, de sua dimensão monumental, das dificuldades encontradas pelos 
pintores (pinturas feitas em tetos de cavernas ou aquelas que se encontram a mais de $1 \mathrm{~km}$ de profundidade no subterrâneo das cavernas sem presença de luz natural) e da organização espacial das pinturas. Ora, sabendo que o esforço empregado pode dimensionar a importância da tarefa para um indivíduo ou uma inteira cultura, a ausência desses dados empobrece o uso desses documentos.

Leroi-Gourhan, que foi, sem dúvida, um dos maiores estudiosos da préhistória francesa, apontou, entre 1960 e 1980, uma série de questões e problemas relacionados à arte na pré-história que são totalmente ignoradas nos livros estudados.

A básica questão da quantidade de pinturas rupestres, que muda consideravelmente no decorrer dos séculos (entre 15.000 e 10.000 anos BP é 10 vezes maior que no período entre 30.000 e 15.000 anos BP), tão fundamental para se entender o próprio significado dessa produção, não é mencionado nem ao menos uma vez. A divisão das pinturas rupestres feita por Leroi-Gourhan, em 4 estilos diferentes, cada um correspondendo a um período diferente da pré-história, também não é citada nos livros, claro sinal da despreocupação dos autores dos livros didáticos em usar essa documentação para mostrar aos alunos que houve mudanças na arte pré-histórica e que essas mudanças correspondem a uma evolução cultural dos homens que a produziram, que essas mudanças não foram uniformes e que é o entendimento de tais mudanças que nos leva ao entendimento dos grupos culturais.

Da mesma maneira, os livros não informam sobre o fato de que pinturas encontradas nas mesmas cavernas podem ter sido pintadas em épocas diferentes, em intervalos maiores que mil anos, nos mais diferentes estilos. O fato de algumas pinturas terem sido retocadas, refeitas ou apagadas em épocas posteriores também é totalmente ignorado e com isso também se abre mão de uma série de considerações sobre as sociedades pré-históricas e sobre o significado da prática das pinturas rupestres.

As legendas das imagens associam as pinturas rupestres a ritos mágicos nos quais os homens pré-históricos pintavam imagens de suas caças para que essas não faltassem ou para o sucesso na caçada, a chamada magia propiciatória. Leroi- 
Gourhan (1982) nos mostra que se fizermos uma comparação entre os animais representados nas pinturas murais das cavernas e os ossos achados nas mesmas, estes não coincidem totalmente. Por exemplo, em Lascaux, a maioria dos ossos encontrados são de renas, um animal que não é encontrado nas pinturas dessa localidade. Com isso os autores dos livros impõem um discurso já pronto aos leitores, não dando espaço para outras interpretações por parte dos alunos, utilizando a cultura material apenas como ilustração do texto e diminuindo a importância do uso da cultura material como documento histórico.

Os artefatos pré-históricos (categorias U, E2 e R1) são apresentados em 77 imagens em 82 presenças (uma repetição de vaso de cerâmica, duas de Vênus paleolítica, uma de moedor de grãos e uma mediação interpretativa de instrumentos pré-históricos). Destas imagens, 15\% são mediações interpretativas (com uma repetição). 


\begin{tabular}{|c|c|c|c|c|}
\hline \multicolumn{5}{|c|}{$\begin{array}{l}\text { ARTEFATOS PRÉ-HISTÓRICOS } \\
77 \text { imagens ( } 82 \text { presenças) }=100 \%\end{array}$} \\
\hline \multicolumn{2}{|c|}{$\begin{array}{l}\text { SEM ORIGEM } \\
61 \%\end{array}$} & \multicolumn{3}{|l|}{$\begin{array}{l}\text { COM ORIGEM } \\
39 \%\end{array}$} \\
\hline & & $\begin{array}{l}\text { BRASIL } \\
67 \%\end{array}$ & & $\begin{array}{l}\text { Outras origens } \\
33 \%\end{array}$ \\
\hline $\begin{array}{l}\text { Representações } \\
\text { (R1) } \\
23 \%\end{array}$ & $\begin{array}{l}\text { Fotos } \\
77 \%\end{array}$ & $\begin{array}{l}\text { Representações } \\
\text { (R1) } \\
15 \%\end{array}$ & $\begin{array}{l}\text { Fotos } \\
75 \%\end{array}$ & $\begin{array}{l}\text { Fotos. } \\
100 \%\end{array}$ \\
\hline $\begin{array}{l}\text { Instrumentos de } \\
\text { pedra ou osso } \\
91 \% \\
\text { Arco e flecha } \\
9 \%\end{array}$ & $\begin{array}{l}\text { Artefatos de } \\
\text { pedra ou osso } \\
67 \% \\
\begin{array}{l}\text { Vasos de } \\
\text { cerâmica } \\
17 \% \\
\text { Esculturas 8\% } \\
\text { Artefatos de } \\
\text { bronze } \\
8 \%\end{array}\end{array}$ & $\begin{array}{l}\text { Vasos } \\
60 \% \\
\text { Esculturas } \\
20 \% \\
\\
\text { Artefatos de } \\
\text { pedra e osso } \\
20 \%\end{array}$ & $\begin{array}{l}\text { Esculturas } \\
27 \% \\
\text { Vasos } \\
27 \% \\
\text { Urnas } \\
\text { funerárias } \\
20 \% \\
\text { Cachimbos } \\
\text { e carimbos } \\
23 \% \\
\text { Artefatos de } \\
\text { pedra } \\
13 \% \\
\text { Tangas de } \\
\text { cerâmica } \\
7 \%\end{array}$ & $\begin{array}{l}\text { Estátuas } \\
50 \% \\
\text { Artefatos de } \\
\text { bronze } \\
20 \% \\
\text { Apanhador de } \\
\text { espíritos de } \\
\text { madeira, corda e } \\
\text { osso } \\
10 \% \\
\text { Machadinhas de } \\
\text { pedra } \\
10 \% \\
\text { Arpões de pedra } \\
10 \%\end{array}$ \\
\hline
\end{tabular}

É Interessante notar que $61 \%$ das imagens de artefatos não apresentam sua localidade de origem. Dos 39\% de imagens que apresentam a localidade de origem do artefato, $67 \%$ são de origem brasileira.

Os desenhos atuais (categoria $\mathrm{MI} 1$ ) correspondem a $15 \%$ das imagens dos artefatos. $100 \%$ dos desenhos atuais que apresentam a origem dos artefatos são de artefatos brasileiros. Os desenhos atuais que não apresentam a origem correspondem a 23\% das imagens de artefatos que não apresentam a origem.

Essa falta de informações sobre a procedência dos artefatos e o grande número de desenhos atuais nas imagens do período nos sugere que os autores dos livros utilizam a Cultura Material apenas para ilustrar o discurso do texto, no qual 
nossos antepassados e suas ferramentas aparecem como atrasados e precários, ao invés de se enfatizar a grandiosidade daquelas enormes descobertas tecnológicas.

Da maneira como as imagens são apresentadas não é levada em consideração uma série de questões que dariam, à pasteurizada figura do "homem primitivo", do "nosso antepassado", uma dimensão minimamente antropológica e social que permitiria compreendê-lo não como um parco arremedo inacabado de nós mesmos mas em sua plenitude de ser humano inserido em um dado ambiente. Com essa postura, de fato, os autores privam os alunos de uma série de informações que são vitais para o entendimento do sucesso do homem como espécie e para um entendimento da evolução cultural deste. Considerar que as soluções encontradas pelo homem para resolver diferentes problemas em diferentes situações e lugares foram as mesmas é empobrecer o processo da grande aventura tecnológica humana, impossibilitando sua compreensão. De fato, a grande ausência na reduzida montagem dessas apresentações é o meio-ambiente, fator ao mesmo tempo propiciador, repelente e/ou integrador das experiências socioculturais do homem.

Desde os anos 1980, com a arqueologia pós-processual, a questão do contexto onde os objetos são encontrados é essencial. Nesse sentido, discutir-se a importância do contexto é fundamental para a compreensão da cultura material como dado significativamente constituído, podendo-se definir tal contexto como:

“(...) a totalidade do ambiente relevante. O contexto de um objeto arqueológico (incluindo uma característica, um sítio, uma cultura) é constituído por todas aquelas associações que são relevantes para o significado. Esta totalidade não é, com certeza, fixa de modo algum, já que o significado de um objeto depende do que está sendo comparado com, por quem, com qual propósito e assim por diante. Há então, uma relação entre a totalidade e a questão da relevância. A definição da totalidade depende da perspectiva, do interesse e do conhecimento. Além disso, há uma relação dinâmica entre o objeto e seu contexto. Ao colocar um conhecimento num contexto, o contexto, ele mesmo é modificado. Há, portanto, uma relação dialética entre o objeto e contexto, entre texto e contexto. O contexto tanto dá sentido a, quanto ganha sentido de um objeto" (Hodder, 1992:14-15). 
Não existe outra maneira de se entender o homem pré-histórico a não ser utilizando os dados materiais deixados por ele, seu percurso histórico sendo indicado pelos instrumentos que ele fez. Que o homem necessita de instrumentos para suplementar as deficiências de seu equipamento fisiológico na obtenção de alimento e abrigo já era postulado por arqueólogos e historiadores desde o século XIX como Tylor (1871), Kossina (1912) e aplicado sistematicamente por Childe (1925). Sabemos que diferentes espécies de hominídeos habitaram a terra e que cada um desses diferentes grupos produziu tipos diferentes de objetos para diferentes finalidades em resposta aos diferentes meio-ambientes em que viveram.

Assim, as ferramentas produzidas por diferentes grupos socioculturais são muitas vezes a única forma de identificarmos tais grupos e qual sua relação com o meio-ambiente, tanto em termos econômicos como sociais. Por exemplo, sabemos que existiram maneiras diferentes de se trabalhar as pedras para a manufatura de ferramentas e que os esqueletos encontrados juntamente com a indústria das lascas pertencem a criaturas especificamente, ou mesmo genericamente, diferentes de nós ou de qualquer ancestral possível. As indústrias do núcleo foram encontradas no sul da índia, Síria e Palestina, em toda a África, na Espanha, França e Inglaterra.Seus autores podem ter pertencido à espécie homo sapiens, ou a formas ancestrais dele (Childe 1966: 65).

Outra conseqüência do quadro pobre e generalizante que os autores do livro didático pintam das ferramentas pré-históricas e de seus inventores e usuários é oferecer ao estudante a noção de que objetos semelhantes têm a mesma função ou significação histórica em diferentes culturas, quando sabemos que, por razões ecológicas ou culturais, a significação histórica dos diversos tipos de artefatos pode variar de uma cultura à outra.

Além do mais, a significação histórica de determinadas categorias de cultura material não é necessariamente a mesma em cada cultura (Trigger 1973:35). Mostrar que houve um acúmulo de conhecimento na manufatura das ferramentas não indica só mais habilidade técnica como, também aplicações mais amplas da tecnologia (Childe 1966:69). 
Se as especificidades das ferramentas e utensílios do homem pré-históricos não são consideradas pelos autores dos livros didáticos, como irão os alunos perceber conceitos básicos para o entendimento da evolução cultural do homem, como aqueles da invenção, difusão e migração? Esses conceitos, gerados no contexto do Evolucionismo, são fundamentais para se discutir, no processo do ensino da História, as vitais questões que circundam as idéias de progresso e de atraso presentes no euro-centrismo.

De fato, a idéia de que o contato inter-grupos gera "alterações culturais" e que os traços materiais são um "kit identitário" que migra entre culturas, passando das "mais evoluídas" às "menos evoluídas", sedimentou a idéia da primazia do "melhor", ignorando que, no contato, ambos os lados envolvidos podem mudar e com igual força e profundidade.

Assim sendo, a discussão bem orientada da Pré-História auxiliaria na sedimentação de conceitos fundamentais para o aprendizado da História, algo absolutamente impossível de se tentar com o material didático apresentado nesta dissertação.

Por outro lado, o fato da maioria das imagens de artefatos pré-históricos com local de origem especificada ser proveniente do Brasil induz a pensar em uma preocupação em valorizar a pré-história nacional.

Duas explicações podem ser sugeridas para esse fenômeno: a primeira é que os PCNs sugerem que os autores não devem trabalhar a História do Brasil a partir da chegada de Cabral, devendo incluir os povos nativos na formação do país. A segunda é que a História Etnocêntrica que privilegiava os feitos dos europeus em detrimento das demais culturas, muito comum nos livros didáticos dos anos 1960-70, foi duramente criticada por estudiosos dos livros didáticos de história (Telles 1984, Carmo 1992, Vasconcellos 1993, entre outros).

Essas explicações se completam e nos fazem crer que a preocupação dos autores em valorizar a pré-história brasileira não é metodológica e sim a de adequar os livros aos parâmetros determinados pelo MEC, fazendo com que os esses tenham mais chances de obterem conceitos altos nas avaliações do PNLD. Um exemplo disso é que as novas tendências e pesquisas relacionadas à pré-história 
brasileira, que a situam em níveis praticados pela arqueologia internacional de ponta como, por exemplo, as investigações da inter-relação entre variáveis ambientais e processos sociais e culturais; o estabelecimento de fronteiras étnicas no passado através de vestígios arqueológicos, principalmente a cerâmica; e a avaliação do impacto da conquista européia sobre os padrões pré-coloniais de organização social e política na Amazônia, não são nem de longe mencionadas nos livros de nossa amostragem (Neves 1999).

É curioso perceber que todos os Manuais do Professor dos livros que apresentam o conteúdo de pré-história alertam os professores sobre a necessidade de se trabalhar com as fontes materiais nesse período e de identificar as transformações físicas e culturais pelas quais o homem passou. Além disso, 63\% dos livros citam, em sua bibliografia, obras de Gordon Childe, arqueólogo e historiador que, a partir de 1925, com seu livro.The Dawn of European Civilization liderou, por mais de 3 décadas, os estudos do uso de objetos na montagem de quadros explicativos da história cultural do homem, sem, contudo, fazerem uso minimamente proveitoso de qualquer de suas proposições.

\section{Cultura Material e registros escritos}

2.1. Mesopotâmia: A cultura material como instrumento para a valorização da escrita.

Uma característica comum aos livros analisados é a utilização da cultura material para se valorizar o aparecimento da escrita na região da Mesopotâmia. Como procuraremos mostrar, a escrita cuneiforme recebe um tratamento diferenciado por parte dos autores dos livros, aparecendo em um número consideravelmente maior de imagens e estando presente em um maior número de livros do que as outras formas de escrita.

Essa categoria, que registramos como RE2 (Registros Escritos cuneiformes), corresponde a $13 \%$ do total de imagens da Mesopotâmia e se concretiza em 16 imagens em 19 presenças, aparecendo em 100\% dos livros.

Em relação às legendas, nenhuma das pertinentes a essa categoria informa a dimensão dos suportes (tabletas e/ou monumentos) onde foram feitas as inscrições 
cuneiformes; apenas $18 \%$ das legendas apresentam o local de origem e $5 \%$ apresentam a época em que as inscrições foram feitas. Curiosamente, nenhuma imagem cuja legenda apresenta o local de origem do objeto, apresenta informação sobre a cronologia do contexto onde tal documento foi encontrado.

\begin{tabular}{|c|c|c|}
\hline \multicolumn{3}{|c|}{$\begin{array}{l}\text { Escrita Cuneiforme } \\
16 \text { imagens em } 19 \text { presenças - 100\% }\end{array}$} \\
\hline \multicolumn{3}{|c|}{ 100\% não apresentam as dimensões } \\
\hline $\begin{array}{l}\text { Com local de origem } \\
18 \%\end{array}$ & $\begin{array}{l}\text { Sem local de } \\
82 \%\end{array}$ & origem \\
\hline $\begin{array}{l}\text { 100\% não apresentam a } \\
\text { época }\end{array}$ & $\begin{array}{l}\text { Apresentam } \\
\text { a época } \\
6 \%\end{array}$ & $\begin{array}{l}\text { Não apresentam a época } \\
94 \%\end{array}$ \\
\hline
\end{tabular}

A ausência de informação sobre a dimensão física das inscrições prejudica a compreensão, por parte dos alunos que utilizarem esses livros, do conjunto da escrita cuneiforme, já que esta também aparecia na forma monumental, como por exemplo, nas paredes dos palácios e templos, embora predomine em tamanhos pequenos como na correspondência pessoal, cartas alfandegárias, notas promissórias, etc.

A dimensão da inscrição está intimamente relacionada com a natureza e o propósito do texto nela apresentado. Mensagens públicas não são escritas em pequenas superfícies de tabletas, assim como as comunicações privadas não aparecem na forma monumental. Portanto, a ausência da dimensão da inscrição impossibilita ao leitor discutir, por exemplo, a questão dos arquivos domésticos, dos arquivos templares e palacianos, o transporte da correspondência pessoal e administrativa, as bibliotecas, o uso privado das tabletas, o processo de inscrição nas paredes dos templos e palácios, a circulação dessas tabletas e o acesso a obras literárias. 
Outra ausência significativa nas legendas das imagens que apresentam a escrita cuneiforme é o idioma em que essas inscrições foram escritas. Sabemos que muitas línguas da antiguidade como, por exemplo, sumério, acádio, hitita, hurrita, elamita, foram notadas em escrita cuneiforme. Como nenhuma das imagens apresentadas nos livros estudados informa o idioma utilizado nas inscrições cuneiformes, também não se introduz ao leitor à questão da difusão da escrita cuneiforme sumério-acadiana no mundo oriental antigo, que no II milênio a.C. tornouse a escrita da diplomacia internacional. Além disso, foram encontradas, por exemplo, inscrições cuneiformes acadianas contendo a correspondência de faraós do Egito com os reis da Babilônia, Assíria e Hatti e até mesmo com funcionários egípcios. Não faltam estudos acadêmicos sobre o período que apontam o alcance da escrita cuneiforme.

Em relação à própria grafia da escrita cuneiforme, os livros de nossa amostragem também não oferecem meios para que os leitores compreendam suas mudanças e estílos. Apenas um livro apresenta uma tabela mostrando a evolução da escrita cuneiforme, da sua forma mais primitiva e pictórica até o cuneiforme clássico.

A ausência do período em que as inscrições foram feitas também colabora para uma homogeneização da escrita cuneiforme. Fica clara a despreocupação, por parte dos autores, em usar essa documentação para mostrar aos leitores que houve mudanças na escrita cuneiforme e que essas mudanças correspondem a uma mudança cultural dos homens que as escreveram e que o entendimento dessas mudanças é necessário para o entendimento desses grupos sociais.

Percebemos com isso que, ao apresentarem imagens da escrita cuneiforme, o objetivo dos autores é apenas o de utilizar objetos para valorizar a "invenção" da escrita e não discutir a complexidade e o alcance dessa invenção revolucionária, inserindo-a no contexto da discussão da cultura material. Toda a organicidade desse novo elemento na história do homem é perdida, já que apresentado de maneira pontual e pobre, como se a escrita já tivesse surgido com as mesmas características e estrutura de nossos dias.

Outro exemplo do uso de objetos para se valorizar o aparecimento da escrita está na grande quantidade de imagens do famoso "Código de Hamurabi". Essa 
imagem aparece em 13 presenças e em 78\% dos livros. Em nenhuma das aparições é revelada a dimensão do suporte físico do "código" e apenas 15\% das imagens indicam o local onde este foi encontrado, perdendo-se o entrelaçamento da escrita com o próprio processo sócio-econômico que concebeu tal código de leis.

O "Código de Hamurabi" é utilizado pelos autores dos livros para enaltecer o início da prática das leis escritas. Toda a discussão proposta nos textos relacionados diz respeito exclusivamente ao conteúdo do código. Em nenhum livro se discute, por exemplo, o fato de o código ter sido escrito em pedra e não em argila, o fato da estela na qual se encontra o texto ter 2.5 metros de altura e o fato do código ter sido encontrado na cidade de Susa, que não fazia parte do império babilônico. A despreocupação dos autores em relacionar o conteúdo do código com suas características físicas impossibilita aos leitores a compreensão da normatização das práticas sociais além de reduzir as informações e as questões que os leitores podem levantar a partir da imagem do código. Questões como o uso público do código e seu valor simbólico, são deixadas de lado pelos autores.

\subsection{Egito e os hieróglifos}

Outro indício da valorização, por parte dos autores dos livros analisados, do aparecimento da escrita na Mesopotâmia pode ser averiguado a partir da comparação do número de imagens que apresentam a escrita cuneiforme em relação ao número de imagens que apresentam hieróglifos (imagens que apresentam exclusivamente hieróglifos, já que estes estão presentes também em pinturas murais, esculturas e papiros). Enquanto a escrita cuneiforme corresponde a $13 \%$ do total de imagens mesopotâmicas e aparece em 100\% dos livros, os hieróglifos correspondem apenas a $3 \%$ das imagens vinculadas ao conteúdo do Egito, se concretizando em 7 imagens e 8 presenças. Estas imagens aparecem em $47 \%$ dos livros.

Assim como no caso mesopotâmico, nenhuma das legendas pertinentes às imagens dessa categoria apresenta as dimensões dos registros hieróglifos e apenas $25 \%$ apresentam o local de origem desses registros. Em relação à cronologia do 
contexto onde o documento foi encontrado, apenas $12.5 \%$ das legendas a apresentam.

\begin{tabular}{|c|c|c|}
\hline \multicolumn{3}{|c|}{$\begin{array}{l}\text { Hieróglifos } \\
7 \text { imagens em } 8 \text { presenças - 100\% }\end{array}$} \\
\hline \multicolumn{3}{|c|}{ 100\% não apresentam as dimensões } \\
\hline $25 \%$ apresentam 0 & local de origem & $\begin{array}{l}75 \% \text { não apresentam o local de } \\
\text { origem }\end{array}$ \\
\hline $\begin{array}{l}50 \% \text { apresentam } \\
\text { a cronologia }\end{array}$ & $\begin{array}{lr}50 \% & \text { não } \\
\text { apresentam } & \text { a } \\
\text { cronologia } & \end{array}$ & 100\% não apresentam a cronologia \\
\hline
\end{tabular}

Essas ausências impossibilitam a compreensão do conjunto da escrita hieroglífica egípcia por parte dos leitores desses livros. Assim como no caso da escrita cuneiforme a dimensão dos registros hieroglíficos está intimamente relacionada com a natureza dos textos e sua ausência prejudica a discussão de questões como a dos arquivos palacianos, da correspondência pública e privada, a escrita monumental, a literatura, etc.

A ausência do local de origem também impossibilita a discussão de questões importantes como a dos escritos em paredes de túmulos e sarcófagos, cujo acesso era proibido às pessoas, as variantes gráficas regionais, o uso da escrita como proteção ou para a maldição (em entradas de templos, por exemplo), o alcance geográfico dos hieróglifos, etc.

A ausência da cronologia do contexto onde foram encontrados os documentos também prejudica a discussão de questões como a evolução da escrita hieroglífica, mudanças provenientes do contato com outras culturas, etc.

Um ponto que não pode deixar de ser abordado é a completa ausência, em todos os livros de nossa amostragem, das escritas hierática e demótica. Essas duas formas de escrita são derivadas dos hieróglifos e ambas são constituídas por desenhos mais simplificados e mais rápidos de serem produzidos. Essas características fizeram com que elas fossem mais difundidas no uso cotidiano 
(religioso e administrativo), deixando posteriormente aos hieróglifos a função da comunicação religiosa o que gerou o uso monumental predominante para essa forma de escrita.

É curioso notar a pequena quantidade de imagens da famosa "Pedra de Roseta", documento chave para a decifração dos hieróglifos egípcios. Esse documento aparece apenas em duas imagens em dois livros diferentes. A habilidade da leitura dos hieróglifos foi perdida no fim da antiguidade e Champollion a recupera em 1822.

A utilização da "Pedra de Roseta" por parte dos autores dos livros analisados seria de grande interesse, pois poderia apresentar ao leitor o processo de decifração dessa escrita, fato esse que foi vital para o entendimento de uma das maiores civilizações da antiguidade. Enquanto as normas de PNLD solicitam uso de documentos, os autores perdem essa grande oportunidade de discutir um caso extraordinário e de grande beleza, que sem dúvida instigaria os alunos que, em determinada faixa etária, são muito atraídos por códigos, a entenderem o mecanismo de decifração, seguindo os passos da descoberta de Champolion, cujo processo se faz presente na maioria da bibliografia específica.

Outra característica dos livros analisados é o grande número de imagens de outras categorias (pintura mural, pintura em papiro, esculturas, relevos, estruturas urbanas e rurais) que também apresentam hieróglifos. O que deve ser notado nesses casos é o fato de que as legendas dessas imagens simplesmente ignoram a presença dos hieróglifos (com apenas uma exceção, uma escultura de Rahotep e sua esposa, cuja legenda explica que os hieróglifos da escultura indicam o nome e o cargo das duas pessoas). Essa despreocupação com os hieróglifos contidos nessas imagens é extremamente prejudicial para a compreensão, por parte dos leitores, de características importantes da pintura ou escultura egípcia. Muitas dessas pinturas e esculturas apresentam os hieróglifos como uma interpretação do seu conteúdo. Os sarcófagos, por exemplo, são repletos de hieróglifos, que identificam seu conteúdo, assim como pinturas murais com temas épicos são acompanhadas de legendas que contam o episódio retratado. 
Ora, da maneira como essas imagens são apresentadas ao leitor, os hieróglifos acabam sendo tomados como banal presença ou simples elemento decorativo nas esculturas e pinturas, o que os expropria de seu real significado e potencialidade.

\subsection{A questão do alfabeto: Fenícios, Gregos e Romanos.}

A escrita alfabética recebe um tratamento diferente, nos livros analisados em nossa amostragem, das escritas cuneiforme e hieroglífica. Ao contrário dessas duas últimas formas de escrita, não são apresentadas imagens exclusivas da escrita alfabética. Em outras palavras, os livros analisados não apresentam nenhuma imagem cuja legenda indique a "escrita alfabética".

A escrita alfabética aparece nas imagens analisadas de três maneiras distintas: em quadros comparativos, quando está inscrita no artefato "foco" da imagem (inscrições em um vaso que apresenta figuras vermelhas, por exemplo) e, finalmente, na forma de registros escritos propriamente ditos, mas que são utilizados não para a discussão da escrita em si, mas do conteúdo do texto (as tábuas de bronze romanas usadas para discussão do direito escrito, ou os cacos de cerâmica utilizados na votação do ostracismo ateniense).

O advento do alfabeto só é discutido em $26 \%$ dos livros analisados. Todos esses livros apontam os Fenícios como os criadores do alfabeto e apresentam quadros comparativos entre as escritas fenícia, grega e a escrita latina utilizada atualmente por nossa sociedade .

Ora, a invenção do alfabeto por parte dos Fenícios não é uma questão pacífica. Havelock, por exemplo, defende que existem três requisitos básicos para que um sistema de escrita seja considerado um verdadeiro alfabeto: "Em primeiro lugar, o apanhado de todos os fonemas de uma língua deve ser exaustivo; segundo, as formas das letras têm de limitar-se a um número entre vinte e trinta; terceiro, cada uma de tais formas, individualmente, não pode cumprir dupla ou tripla função. As identidades acústicas devem ser fixas e imutáveis" (Havelock, 1996, 77). Segundo esse autor, o sistema fenício não cumpre esses três requisitos, pois nesse sistema, a 
sílaba é a unidade básica da fala, tornando-o pouco flexível e repleto de ambigüidades.

Já o sistema grego, dissolve a sílaba em seus componentes acústicos, introduzindo o registro escrito das vogais o que acabou com a ambigüidade dos sistemas silábicos; com isso os gregos inventaram não só o alfabeto mas também a cultura letrada e a base letrada do pensamento moderno (Havelock, 1996). Essa invenção tornou possível a democratização do conhecimento da escrita. Os sistemas de escrita anteriores ao grego (incluindo o fenício) encontraram duas soluções para a representação gráfica dos sons: ou criaram um sistema onde cada sílaba era representada por um sinal gráfico diferente, o que acabou criando a necessidade de centenas de sinais gráficos ou procuraram fazer uma economia de sinais gráficos, fazendo com que um mesmo sinal representasse mais de um som, deixando para o leitor resolver que som cada sinal representava, possibilitando um grande número de ambigüidades.

O primeiro caso exigia uma grande capacidade de memorização enquanto o segundo exigia um conhecimento profundo da língua para resolver as ambigüidades do texto. Em ambos os casos, o processo de domínio da escrita era muito complicado e demorado, criando, a figura do perito-leitor. Já o sistema grego, graças a sua superior análise do som, pôs a capacidade de ler teoricamente ao alcance de crianças em um estágio em que ainda estavam aprendendo os sons de seu vocabulário oral. Esse fato somado a criação e a manutenção de um ensino da leitura em um nível elementar possibilitou a democratização da escrita.

Apesar dos livros de nossa amostragem que tratam da questão da invenção do alfabeto valorizarem o sistema fenício, nenhuma imagem nestes livros apresenta a escrita fenícia propriamente dita, com exceção de quadros comparativos criados para o livro. A ausência de imagens que mostrem os suportes e os meios em que eram feitas as inscrições fenícias impossibilita aos leitores a discussão de questões como o uso doméstico da escrita e a relação entre o uso comercial da escrita e sua difusão pelo Mediterrâneo e Oriente Próximo.

A escrita alfabética aparece também em imagens diversas como figuras vermelhas e negras, pinturas, mosaicos, moedas e estruturas urbanas e rurais, mas 
nesses casos a presença da escrita é ignorada pelas legendas, que se preocupam em identificar as cenas representadas nas pinturas e mosaicos e a função das estruturas urbanas e rurais.

A última maneira como a escrita alfabética aparece nas imagens dos livros analisados é na forma de registros escritos propriamente ditos. Estas imagens não têm como função apresentar aos leitores a escrita alfabética e sim a discussão das leis escritas (tábuas de bronze romanas) e da democracia ateniense (cacos de cerâmicas utilizados na votação do ostracismo).

Os votos de ostracismo se concretizam em 3 imagens diferentes e 5 presenças, em 33\% dos livros. Sabemos que o conjunto dos votos é considerado o maior grupo de inscrições atribuíveis aos cidadãos em geral e o mais antigo, aparecendo em Atenas na primeira metade do século $V$ a.C. As imagens dos votos do ostracismo não deveriam ser usadas apenas para ilustrar esse fenômeno da democracia ateniense, mas também para se discutir a difusão da escrita alfabética entre os cidadãos atenienses. O sistema de voto escrito substituiu, ou somou-se ao sistema de votos oral, transformando o voto em um objeto visível e dando maior exatidão ao processo de votação. As imagens dos votos seriam um ótimo ponto de partida para a discussão de questões fundamentais para o entendimento da democracia ateniense como a difusão da escrita entre os cidadãos atenienses, a compra e venda de votos, as falsificações de votos, entre outras.

Não é apenas a partir de registros escritos que podemos discutir a questão da escrita no mundo antigo. No caso romano chama a atenção a presenças de duas pinturas murais, provenientes de Pompéia: uma representa uma mulher portando estilete e tabuinhas utilizadas para a escrita; outra representa um casal de aristocratas. $\mathrm{O}$ homem segura um rolo utilizado como livro e a mulher o instrumento utilizado para escrever nesses rolos. Essas imagens aparecem em 40\% dos livros analisados. As legendas dessas imagens apresentam apenas o local onde foram feitas essas pinturas. Essas imagens poderiam ser utilizadas pelos autores para a discussão de questões importantes: as mulheres sabiam ler e escrever? Porque pintar na parede de uma casa uma imagem de uma mulher que porta os 
instrumentos necessários para escrita? Existia o uso doméstico da escrita? Quais as classes sociais tinham acesso à escrita?

\section{Conclusões parciais}

Ao analisarmos a presença da escrita nas imagens de cultura material da antiguidade nos livros didáticos podemos chegar a algumas conclusões: a cultura material é utilizada pelos autores dos livros de nossa amostragem para valorizar a invenção da escrita e para retratar as formas de escrita pictóricas. Não existe a preocupação por parte desses autores de introduzir uma questão intimamente relacionada com a escrita: a questão da leitura. Sabemos que a democratização da leitura só ocorreu após a invenção do alfabeto grego. Da maneira como os registros escritos são apresentados nos livros analisados, a questão da leitura não recebe o devido destaque, impossibilitando aos leitores a discussão de questões como o uso público da escrita e o papel religioso/monumental da escrita.

É interessante notar como a invenção da escrita é valorizada em detrimento da invenção do alfabeto. Foi exatamente o alfabeto grego que possibilitou a democratização da escrita e da leitura e que criou a base letrada da cultura moderna.

Talvez a resposta para essa diferenciação no tratamento das duas invenções fundamentais para se entender a história do homem e da cultura ocidental esteja nos fatores estéticos. A escrita cuneiforme e a hieroglífica têm uma forma extremamente diferente do nosso sistema de escrita e, portanto ambas as escritas seriam "merecedoras" de serem apresentadas em imagens. Como a escrita alfabética é semelhante ao sistema que utilizamos, os autores parecem não julgar necessária a presença de imagens desse sistema.

Novamente, perde-se a oportunidade de oferecer, ao professor, um importante instrumento de trabalho com alunos em fase de codificar e de interessarse por códigos. Se não bastasse, a questão da democratização da escrita e da leitura continuam vitais para o desenvolvimento socio-econômico de nossos dias e a sala de aula seria o espaço ideal para discuti-la. 


\section{Recipientes de cerâmica}

Devido à sua grande durabilidade e resistência, os objetos de cerâmica são presença freqüente em sítios arqueológicos das mais diversas sociedades e regiões.

A grande diversidade de formas, técnicas de produção (antiplástico, processo de queima, engóbio), e decoração (pintura, relevos) fizeram deste tipo de material o mais usado pelos estudiosos para trabalhos de tipologia e seriação que, junto com a estratigrafia, são as bases da arqueologia moderna. A Antropologia Cultural, a Etnografia e os estudos de Cultura Material também fazem uso de objetos para apresentar, por meio de sua manufatura, uso, comércio e descarte, a história do homem que os produziu.

Sabemos que a cerâmica foi amplamente utilizada no mundo antigo, com os mais diversos usos e funções (telhas, pisos, encanamentos, ladrilhos de parede), uma das principais sendo a produção de recipientes (vasos, bacias, baldes, tigelas, pratos, copos, misturadores, etc).

Para melhor situar a questão, decidimo-nos por circunscrever a análise àquelas culturas representadas com maior destaque nos livros didáticos: Egito e Mesopotâmia, Fenícios, Grécia e Roma.

\subsection{Egito e Ásia Menor.}

Uma característica comum a todos os livros analisados para a elaboração desta monografia é a pequena quantidade de imagens de recipientes de cerâmica relacionadas a culturas não-helênicas.

É também importante notar que em todos os livros analisados, a apresentação relativa à Mesopotâmia não contém nenhuma imagem de recipientes de cerâmica, fato esse que consideraremos posteriormente.

Em relação ao Egito e á Ásia Menor, as imagens de recipientes de cerâmica presentes nos LD correspondem a menos de 1\% das imagens relacionadas ao Egito e a $2 \%$ das imagens relacionadas aos Hebreus. 
Esse magro percentual de 3\% de imagens referentes a Hebreus e Egípcios contrasta vivamente com a grande quantidade e variedade de imagens de recipientes de cerâmica gregos, de todos os períodos (ver item abaixo).

Essa ausência de imagens não corresponde à enorme disponibilidade de material proveniente dos registros arqueológicos dessas regiões culturais, que apresentam um número e variedade de recipientes de cerâmica notável, tanto pela quantidade quanto pela qualidade de manufatura.

Se tal inexplicável ausência não fosse já o bastante, duas outras ocorrem: todas as imagens de recipientes de cerâmica relacionados a essas civilizações, presentes nos livros objeto desta pesquisa, não apresentam a origem dos objetos e tampouco a cronologia do contexto onde foram encontrados.

Com referência às peças egípcias, por exemplo, é apresentada apenas uma única imagem de recipiente de cerâmica, a de vasos canópicos, recipientes feitos para receberem os órgãos retirados no processo de mumificação. Além dessa imagem solitária, os recipientes de cerâmica aparecem em duas imagens de esculturas representando fabricantes de cerveja no ato de despejar o líquido em grandes recipientes, com o objetivo de mostrar o processo de fabricação e não os recipientes usados.

O que chama a atenção é que a única imagem que apresenta apenas recipientes de cerâmica referentes ao Egito, mostra um conjunto de recipientes cuja função era exclusiva e diretamente vinculada a uma das características egípcias mais destacadas nos livros analisados: a mumificação. Com isso o leitor perde a importância cotidiana dos recipientes de cerâmica em contextos que não o funerário e uma interessante possibilidade de comparar essas duas culturas mediterrânicas, já que também no Egito a cerveja era parte da dieta quotidiana, até mesmo de crianças.

Os recipientes de cerâmica foram largamente empregados pela civilização egípcia para os mais diversos fins do transporte ao armazenamento de sólidos e líquidos, em diferentes tamanhos e formatos. A produção de bens manufaturados e de alimentos também empregava diversos tipos de recipientes de cerâmica, assim 
como a vida doméstica. Portanto a ausência de imagens de recipientes de cerâmica empobrece a compreensão dessa sociedade.

Outra cultura pré-helênica tratada nos livros didáticos com certo destaque é a dos Fenícios. Eles são valorizados nos textos analisados por terem criado o alfabeto e por terem sido excelentes navegadores e comerciantes.

Assim como a invenção do alfabeto é valorizada, sem que nenhuma imagem apresente o alfabeto fenício (vide acima p.58) a valorização das atividades mercantes no texto não é correspondida por imagens. Os recipientes de cerâmica eram largamente utilizados no transporte marítimo que Fenícios faziam de líquidos e sólidos e como o próprio produto a ser comercializado. No entanto, nossa amostragem de livros didáticos nos revela a presença de apenas uma imagem de um recipiente de cerâmica fenício.

A ausência dos recipientes de cerâmica utilizados pelos fenícios para transporte ou como bens de consumo prejudica o entendimento do tão valorizado comércio dessa cultura. A presença de imagens desses recipientes ajudaria os alunos a entenderem questões sobre os produtos, a maneira como eram transportados e sobre o comércio fenício como, por exemplo, se as mercadorias de outras culturas eram transportadas em recipientes fenícios ou em recipientes das culturas que as produziram; a influência da tecnologia de outras culturas na produção cerâmica fenícia; a relação entre o formato dos recipientes, sua decoração e sua carga e a relação entre o formato dos recipientes e a maneira como estes eram transportados nos navios.

\section{2. "Vasos gregos": recipientes ou suporte para pinturas?}

Se os recipientes de cerâmica não receberam a devida importância nas imagens das sociedades citadas acima, o mesmo não acontece com os recipientes de cerâmica gregos, que correspondem a 94\% das imagens de recipientes de cerâmica apresentadas em todos os livros analisados. Mas o fato dos livros apresentarem uma grande quantidade de imagens de recipientes de cerâmica grega não significa que estes receberam o tratamento adequado por parte dos autores dos livros analisados. 
Os recipientes de cerâmica gregos são objetos que atraem a atenção de especialistas (antiquários, historiadores da arte, connoisseurs, comerciantes de arte, curadores e historiadores) há bastante tempo ${ }^{16}$. Dentre as diversas maneiras de se estudar os recipientes de cerâmica gregos, podemos destacar, entre os mais recentes, a de Sparkes (1991), que sugeriu que as evidências nas quais baseamos nossa compreensão na produção dos recipientes podem ser divididas em quatro categorias (técnicas de manufatura e resíduos internos; oficinas e os fornos onde estes foram produzidos; registros escritos antigos; figuras de pintores e ceramistas apresentadas nos próprios recipientes).

Tais categorias vão muito além do simples estudo estilístico da cerâmica grega, tônica dominante até os anos 60 do século XX. Elas permitem a discussão, por exemplo, do uso cotidiano dos recipientes; das diferenças regionais na produção dos recipientes; do comércio a curta e longa distância, da relação entre decoração e forma dos recipientes e de seu valor econômico e simbólico.

Nossa amostragem revela que as imagens de recipientes de cerâmica correspondem a $27 \%$ das imagens relacionadas à Grécia antiga.

\begin{tabular}{|c|c|c|c|}
\hline \multicolumn{4}{|c|}{$\begin{array}{l}\text { Recipientes de Cerâmica Gregos } \\
80 \text { imagens em } 99 \text { presenças }\end{array}$} \\
\hline \multicolumn{4}{|c|}{ 100\% não apresentam as dimensões } \\
\hline \multicolumn{2}{|c|}{$2 \%$ apresentam cronologia } & \multicolumn{2}{|l|}{$98 \%$ sem cronologia } \\
\hline $\begin{array}{l}50 \% \text { apresentam } \\
\text { origem }\end{array}$ & $\begin{array}{l}50 \% \\
\text { apresentam não } \\
\text { origem }\end{array}$ & $\begin{array}{l}1 \% \text { apresenta } \\
\text { local de origem }\end{array}$ & $\begin{array}{lr}99 \% & \text { não } \\
\text { apresentam } & \text { local } \\
\text { de origem } & \end{array}$ \\
\hline
\end{tabular}

O legendamento dos objetos e sua menção dentro do texto não contemplam a dimensão dos recipientes representados, prejudicando a compreensão que os leitores poderiam ter da cultura grega a partir deles. Existem recipientes das mais diferentes dimensões, variando de pequenos recipientes para óleo ou perfume a gigantescos vasos utilizados para o armazenamento de provisões como grãos, vinho e azeite. Objetos com a mesma forma, ânforas, por exemplo, foram encontradas nas escavações arqueológicas em diversos tamanhos e a dimensão do objeto está

\footnotetext{
${ }^{16}$ Para uma trajetória do estudo dos recipientes gregos ver Cook 1997 e Sparkes 1996.
} 
diretamente relacionada com sua função e uso, além de poder ser, em muitos casos, um indicador do número de pessoas que habitavam uma casa ou um conjunto de habitações.

De fato, há quarenta nos, aproximadamente, que a teoria da arqueológica chamada de "nova arqueologia" nos anos 1960/70, apontava para a possibilidade de se estudar a demografia de uma determinada localidade e mesmo sua organização social, a partir da quantidade e capacidade de armazenamento (carryng capacity) demonstrada pelos vasos cerâmicos. Embora tal perspectiva seja mais facilmente adequada aos estudos pré-históricos, várias abordagens sob a égide da "nova arqueologia" foram encetadas no mundo clássico, apresentando, justamente, hipóteses sobre o funcionamento quotidiano de habitações em função da quantidade, tipo e distribuição da cerâmica em seus ambientes.

O conhecimento de tais possibilidades sem dúvida leva à privação seguinte a que se submete os leitores dos livros analisados: a ausência do local onde foram encontrados os recipientes de cerâmica.

Além da importância do local de encontro doméstico, espacialmente considerado, como dito acima, sabemos que os recipientes de cerâmica gregos eram um dos produtos comercializados pelos gregos e foram encontrados por toda bacia do Mediterrâneo (Europa, África e Ásia Menor) e em lugares ainda mais distantes da Grécia, podendo ser usados como um dos principais indicadores de contato entre gregos e outras culturas e da expansão marítima grega.

Um exemplo interessante do comércio de recipientes de cerâmica gregos com regiões não helênicas é a presença de recipientes de cerâmica grega na região da Etrúria. Os etruscos criaram uma demanda de formas e temas de decoração que passam a ser especialmente criados para eles com os artesãos atenienses atendendo essa demanda, conscientemente repetindo algumas formas próprias dos etruscos e dando-lhes um tratamento próprio da produção vascular ateniense. Como exemplo podemos citar o recipiente de cerâmica ateniense que tinha a mesma forma de ânforas de bucchero etrusco, mas era decorado com figuras negras.

A ausência das localidades onde foram encontrados os recipientes também impossibilita que o leitor compreenda o fenômeno das reproduções locais do padrão 
grego $^{17}$ de manufatura, estilo, forma e pintura de recipientes como, por exemplo, a cerâmica italiota, encontrada em toda região de colonização grega da Magna-Grecia. Essa abordagem permitira tratar de amplo elenco de problemas relacionados à colonização no mundo antigo, a começar de mitos, sua transferência para outras regiões e adaptações locais já perceptíveis nas primeiras décadas do contacto. A questão vem sendo amplamente estudada há mais de 40 anos, reunindo os especialistas em congressos anuais chamados de "Convegni sulla Magna Grecia", cujas Atas se encontram todas disponíveis na biblioteca do MAE-USP. Não falta, portanto, bibliografia disponível para orientar os autores.

Apesar do grande referencial à disposição, o quer mais circula, portanto, é o repertório clássico tradicional. A primeira característica das imagens de recipientes de cerâmica gregos apresentados nos livros analisados é a completa ausência de imagens de recipientes que não tenham sido decorados com figuras vermelhas ou negras, pertinentes, justamente, ao período clássico, séculos VI-IV a.C.. Os recipientes de períodos anteriores, formativos, dos séculos VIII-VII a.C., com outros estilos de decoração, como por exemplo, os estilos protogeométrico, geométrico e orientalizante, não aparecem em nenhuma imagem assim como os recipientes de fundo branco, aqueles de superfície preta não-figurada (pouco estudados pelos especialistas, apenas recentemente aparecendo nos repertórios, tamanha era a preponderância dos estudos de cerâmica figurada) ou aqueles que não receberam pintura alguma, de confecção mais tosca, normalmente usada para cocção de alimentos e por isso chamada de "doméstica".

Essas ausências impossibilitam que o leitor discuta questões como o uso da cerâmica decorada como indicador de classe social ou de status; a evolução nas técnicas de decoração dos recipientes, as influências de outras culturas nessa decoração e o raio de alcance de um estilo de decoração; e a relacionar a forma do recipiente com a decoração (ou a ausência desta).

\footnotetext{
${ }^{17}$ Usa-se aqui o termo "grego" por não ser este o melhor local para discutirmos as inúmeras variantes da cerâmica da região que se convencionou chamar de Grécia. Trata-se, na maior parte das vezes, de cerâmica de produção ateniense.
} 
A preponderância dos estudos da cerâmica grega figurada deslizou para os LD de tal maneira a ponto de se chegar a prescindir do vaso em si, com $74 \%$ de imagens apresentando apenas a decoração (pinturas de figuras negras ou vermelhas) dos recipientes, omitindo totalmente sua forma.

\begin{tabular}{|l|l|lll|}
\hline Recipientes de Cerâmica Gregos \\
\hline 26\% apresentam a forma do recipiente & $\begin{array}{l}74 \% \text { não apresentam a forma do } \\
\text { recipiente }\end{array}$ \\
\hline & $\begin{array}{l}59 \% \text { Figuras } \\
\text { vermelhas }\end{array}$ & $\begin{array}{l}41 \% \\
\text { negras }\end{array}$ & Figuras \\
\hline
\end{tabular}

A valorização das imagens representadas nos recipientes em detrimento) da apresentação do vaso em sua inteira complexidade, com forma e a decoração, retiram desses objetos a riqueza de possibilidades de estudo que encerram, transformando-os em meros suportes ocasionais.

Diferentes formatos de recipientes correspondem a diferentes funções em diversos contextos da cultura grega. Os recipientes de cerâmica estavam presentes, por exemplo, no ambiente doméstico, nos templos, no comércio e nos cemitérios e em cada um desses contextos apareciam em formas e funções diferentes. Sabemos, por exemplo, que o recipiente chamado de lekythos era utilizado para armazenar perfumes e que aqueles decorados com fundo branco estão intimamente relacionados a contextos funerários.

As diferentes formas de ânforas (ânfora, ânfora com pescoço, ânfora panatenáica, pelike) (que) eram utilizadas para o transporte de azeite, vinho, cereais, peixe e como decantadores. A diferentes formas de Hydria tinham como função armazenar água assim com as diferentes formas dos Oinochoai (oinochoe em forma de sino, onichoe cônico, olpe, lagynos) serviam para deixar o vinho "respirar". As diversas formas dos Kraters (Kotyle-krater, volute-krater, krater -coluna, krater-sino, stammos, dinos) eram utilizados para misturar água ao vinho; os Lekythoi (lekythos,askos, alabastron, aryballos) eram pequenos frascos utilizados como recipientes para perfumes, óleos de banho e alguns condimentos; os pyxides eram 
utilizados como recipientes para cosméticos ou bugigangas; as diferentes formas de taças (taças, canecas, xícaras, kantharos) eram os recipientes para beber.

Estes exemplos indicam alguns usos dos recipientes de cerâmica gregos: beber, comer, versar, transportar e armazenar. A partir dessas informações podemos estudar alguns aspectos da sociedade grega como, por exemplo, o cotidiano; a indústria e a tecnologia; a moda; comércio e economia.

Essa valorização das figuras pintadas nos recipientes, somada à ausência de imagens com outras formas de decoração pode levar o leitor a pensar que a principal preocupação dos gregos em relação aos recipientes era a decoração destes, transformando um objeto repleto de funções e de possíveis leituras em um objeto de mão única, ilustrador imóvel de preferências visuais que não são jamais explicadas.

Essa valorização da função estética da iconografia grega não é exclusividade dos autores de livros didáticos, tendo já sido apontado que:

\footnotetext{
"Um agravamento ocorria, todavia, no caso da iconografia: o seu pretenso potencial estético, devidamente processado pela cultura ocidental, reforçava a idéia de que sua função no interior da obra fosse prioritariamente ilustrativa. Aqui uma possível virtude transformava-se em incapacidade irremediável: o documento, que poderia também ter funções estéticas, deixa de ser documento para exclusivamente aguçar os sentidos".(REDE, 1993:266).
}

Em outras palavras, ao estudar as tendências atuais no estudo da relação entre iconografia e história da Grécia antiga, constatava o autor que a imagem, ao ser utilizada pelo historiador, não obtivera melhor sorte do que o restante dos elementos de cultura material.

Sabemos que os recipientes de cerâmica decorados com figuras negras e vermelhas tinham, além de seu uso funcional, uma importante função como agentes de comunicação. Eles funcionavam como sinais identitários e simbólicos, revelando informações em termos de preferências por determinados mitos em determinados momentos da história grega. Essa função simbólica e identitária dos recipientes também não é explorada pelos autores dos livros. 
É interessante notar que esses aspectos da sociedade grega que podem ser discutidos a partir da cultura material são amplamente abordados nos textos dos livros analisados. Infelizmente a discussão apresentada nos livros é baseada exclusivamente em fontes escritas e em nenhum livro são apontadas as possibilidades do uso da cultura material para a discussão desses aspectos.

É interessante notar que esses aspectos da sociedade grega que podem ser discutidos a partir da cultura material são amplamente abordados nos textos dos livros analisados. Infelizmente, a discussão apresentada nos livros é baseada exclusivamente em fontes escritas e em nenhum livro são apontadas as possibilidades de ser a cultura material a nos possibilitar a discussão desses aspectos.

O principal uso dos recipientes de cerâmica gregos nos livros analisados é efetivamente o de utilizar a imagem pintada no recipiente (figuras negras e vermelhas) para ilustrar o texto. Os textos relacionados aos jogos olímpicos, por exemplo, estão amplamente ilustrados com atletas correndo ou lutando e os textos sobre a vida cotidiana dos gregos apresentam imagens também retiradas dos recipientes com figuras negras e vermelhas, cuja temática são os artesãos, agricultores, simpósios, etc.

Este uso das imagens contidas nos recipientes é bastante arriscado, já que a imagem pintada não é uma cópia da realidade grega. Elas são representações criadas pelos artesãos, cuja finalidade podia ser, entre outras, simbólica, agradar o cliente, valorizar um evento, homenagear uma pessoa ou tornar a composição mais harmoniosa. Ao ilustrar o texto com essas imagens, os autores sugerem aos leitores que aquela imagem reproduz a realidade da Grécia antiga, ou seja, que a maneira como as imagens retratam o cotidiano era exatamente a maneira como este ocorria no passado. Percebemos com isso que o objetivo dos autores dos livros, ao ilustrarem seus textos com imagens de figuras negras e vermelhas é possibilitar ao leitor uma "visualização do passado", usando-as como sombras de uma realidade perdida.

Evidentemente, nada impediria que as figuras contidas na cerâmica grega fossem usadas para fins didáticos, como válido instrumento para analisar a cultura 
grega antiga. Tal uso, contudo, não poderia ser apenas nominalmente ilustrativo.Para além de simplesmente informar que a coruja era o símbolo de Atena - embora nem mesmo isso seja feito - existe toda uma cadeia de recursos de análise que nos apontam os diferentes significados da presença da coruja nas representações vasculares. De fato, sozinha, ao lado, na mão da deusa, com ou sem o ramo de oliveira, pousada ou voando, a coruja não é um elemento detentor de um único significado. Ela retrata, de fato, uma série de mensagens codificadas, cheias de significado na cultura grega, que sua simples reprodução isolada não consegue informar (Bron \& Kassapoglou 1992).

Todas as considerações acima podem ser aplicadas à ausência de apresentação de recipientes de cerâmica mesopotâmicos.Contudo, quando se sabe que uma das principais produções para exportação das culturas mesopotâmicas era, justamente, os recipientes de cerâmica, bens de grande prestígio em todo o Mediterrâneo, nossa perplexidade se aguça e nos encaminha para a certeza do desconhecimento, por parte dos autores dos livros didáticos, do que seja a cultura material dos povos por eles apresentados.

\section{Desenhos atuais e o uso pedagógico da imagem pelo historiador}

Uma das características mais marcantes em todos os livros analisados para essa dissertação é a enorme quantidade de imagens da categoria MI 1 (desenhos atuais). Essa categoria é formada por imagens que foram produzidas para os livros analisados, constituída de desenhos e pinturas atuais que representam a vida cotidiana, as estruturas urbanas e rurais e outras características que se supõem pertencerem às culturas apresentadas nos livros.

Sabemos que estas não são as únicas mediações interpretativas contidas nos livros, já que todas as fotografias de artefatos, pessoas ou lugares também são uma medição interpretativa, uma vez que o sujeito representado é sempre construção filtrada pelo autor da foto.

Os desenhos atuais, contudo, mais claramente denotam a percepção que os autores dos livros didáticos têm do passado e sua necessidade de adequar suas 
idéias a uma temática variada, mostrando artefatos, registros escritos, situações cotidianas das culturas apresentadas nos livros analisados e até mesmo conceitos (o yn e yang dos chineses, por exemplo). Destes desenhos, os que se referem ao cotidiano das culturas estudadas correspondem a $60 \%$ do total dos desenhos atuais presentes nos livros analisados.

\begin{tabular}{|l|l|l|l|}
\hline $\begin{array}{l}\text { Total de imagens por } \\
\text { cultura }\end{array}$ & $\begin{array}{l}\text { Total de imagens } \\
\text { por cultura }\end{array}$ & $\begin{array}{l}\text { Quantidade de } \\
\text { imagens de } \\
\text { desenhos atuais }\end{array}$ & $\begin{array}{l}\text { Porcentagem de imagens de } \\
\text { desenhos atuais em relação } \\
\text { ao total de imagens da cultura }\end{array}$ \\
\hline Pré-História & 254 & 99 & 38 \\
\hline Mesopotâmia & 117 & 23 & 17 \\
\hline Egito & 220 & 40 & 16 \\
\hline Pérsia & 45 & 6 & 12 \\
\hline Hebreus & 45 & 6 & 12 \\
\hline Fenícios/Cretenses & 47 & 6 & 12 \\
\hline Grécia & 317 & 36 & 11 \\
\hline Roma & 376 & 50 & 11 \\
\hline
\end{tabular}

Estes desenhos atuais, que buscam interpretar a vida cotidiana das sociedades do passado, apresentam uma temática variada, mostrando desde o mundo do trabalho (agricultores, artesãos, caçadores) passando por cerimônias religiosas, guerras até a vida doméstica e pública. Trata-se claramente de uma tentativa de se recuperar o contexto sistêmico das culturas ali representadas (Schiffer 1972). Ou seja, os autores dos livros acreditam que a partir da mediação dos desenhos atuais é possível recuperar e visualizar com fidelidade interpretativa as sociedades do passado.

A recuperação do contexto sistêmico a partir do sistema arqueológico já não é uma tarefa de fácil execução para os arqueólogos. Para isso é necessário o uso de filtros que possibilitem o entendimento do descarte e deposição dos elementos ao longo do tempo, essência da formação de um sítio arqueológico. Um mesmo contexto arqueológico pode ter sido palco de diversos contextos sistêmicos. Uma arena antiga, por exemplo, não apresenta um único contexto sistêmico: temos a arena lotada e barulhenta durante os jogos; a arena silenciosa e vazia em outros dias; temos os treinos dos gladiadores; a limpeza e a manutenção da arena em dias de recesso dos jogos, etc. Portanto só é possível pensar na recuperação do contexto 
sistêmico a partir do entendimento da formação do contexto arqueológico, algo inexistente nos livros analisados.

Outro problema na apresentação de um contexto sistêmico por meio de desenhos atuais é a generalização por eles veiculada. Em um mesmo livro, a sociedade grega, por exemplo, é reduzida a alguns desenhos, que não especificam o lugar ou período que representam. Com isso o leitor pode acreditar que os Gregos, independente de seu local de origem ou residência e do período em que viveram, apresentavam os mesmos hábitos cotidianos, se vestiam da mesma forma e habitavam os mesmos tipos de estruturas urbanas e rurais.

Ao sintetizar e pasteurizar cenas imaginárias de um cotidiano suposto, os livros didáticos criam a ilusão de situações perfeitamente bem conhecidas, banais e familiares, sufocando na origem qualquer possibilidade de discussão que elaborasse o conhecimento e suscitasse vontade e determinação de conhecer mais, para além das dúvidas. De fato, a resposta pasteurizada aplaca, satisfaz e... amortece.

Claro está que o uso de imagens como recurso pedagógico para a visualização do passado não é recente, sendo até quase exclusivas em livros dos anos 30 a 60. A questão de seu uso é recorrente em debates historiográficos desde os anos 1930 e por serem muitos os trabalhos que abordam a temática do ensino de História e as imagens, tentaremos facilitar sua análise apresentando-os em três grupos:

Trabalhos metodológicos: são aqueles que tratam da didática da História, de como se ensinar a História ou que sugerem usos e linguagens para o ensino da História (ex. Castro 1952,Guedes 1963, LEITE 1969, Camargo 1997, Savieto 1997, entre muitos outros).

Análises: são trabalhos que analisam e discutem o uso de imagens em casos específicos, como no ensino durante o período da ditadura militar (1964-85), a imagem do negro, do índio ou da mulher nos livros didáticos (Almeida Neto 1997, Bittencourt 1997, Carmo 1991, Silva 2000, Zundt 2001 entre outros). 
Relatos de Experiências: são trabalhos que oferecem experiências particulares relacionadas ao ensino e a imagens (Carneiro 1988, Dias \& Garcia Neto 1988, Luporini 1989).

Essas categorias não são rígidas ou imóveis, ou seja, cada trabalho pode flutuar entre uma ou mais categorias, que foram por nós criadas exclusivamente para facilitar a análise e a discussão dos trabalhos.

\section{A. Trabalhos Metodológicos:}

Neste grupo heterogêneo estão contidos trabalhos sobre metodologia e didática da História. Os trabalhos mais gerais, que pretendem ensinar ou ajudar o historiador a ter um melhor rendimento na sala de aula eram comuns entre os anos $1930-70$. Esse tipo de trabalho continuou sendo produzido durante as décadas seguintes, mas em menor número, devido às renovações teórico-metodológicas ocorridas no anos 1970-80, onde se afirmou a inexistência de uma maneira única de se ensinar e estudar a história, fazendo com que esses guias que sugeriam uma "receita" para o ensino de História perdessem a importância. Os nomes sempre são sugestivos como Princípios do Método no ensino de História; Curso de Didática de História; O ensino de História no Primário e Ginásio; Ensinando e aprendendo História; Como se ensina a História.

Em quase todos estes trabalhos, existem considerações sobre o uso da imagem no ensino de História. Essas considerações dizem respeito às duas principais propostas do uso das imagens na sala de aula: para atrair e motivar o interesse dos alunos em relação à História e para ajudar na visualização do passado. Ou seja, os usos propostos para a imagem eram o de ilustrar o conhecimento previamente adquirido e o de tornar mais prazerosa a aula de História, que era centrada no texto.

A função inicial do uso da imagem em sala de aula, para Castro (1952: 59) era o de auxiliar na formação estética do aluno. Segundo a autora, "esta finalidade é de grande importância para a ampliação da vida emocional do indivíduo e de seus 
interesses, e abrange tanto a formação do gosto em geral como a capacidade de discriminação aplicada à pintura, escultura arquitetura e até mesmo a música sendo possível". Guedes (1963:109) também argumenta nessa linha, já que, para ele, é importante "reunir a ilustração histórica à documentação arquivística pois uma instrui e a outra forma a sensibilidade do adolescente".

Nestes trabalhos, o uso de imagens está vinculado às chamadas atividades extracurriculares. Estas atividades "ampliam e enriquecem o conteúdo das aulas, constituindo elemento de alto valor tanto do ponto de vista da motivação como referente ao esclarecimento e aprofundamento da própria matéria" (castro 1952:108). As principais atividades extracurriculares sugeridas são: TV, cinema, cinematógrafo, vídeo, slides, quadrinhos, mapoteca, pinacoteca, excursões a museus e locais de "importância histórica", teatro de classe e museu de classe.

Não é qualquer tipo de imagem que deva ser usada nas aulas de História: a temática tem de ser histórica. Leite (1969), por exemplo, argumenta, ao falar sobre a utilização das histórias em quadrinhos na sala de aula, que o professor deve escolher uma HQ que tenha um tema histórico como, por exemplo, o faroeste americano, e que os quadrinhos são uma ótima maneira do professor melhorar seu relacionamento com os alunos. O mesmo tipo de sugestão é feita para o uso de pinturas e filmes: o tema deve ser histórico para ajudar na visualização do passado.

Os outros trabalhos deste grupo são artigos inclusos em obras sobre o ensino de História, resumos e anais de seminários e congressos. Estes artigos tratam normalmente de alguma problemática específica como a utilização de quadrinhos, de documentos históricos, de fontes materiais e da imprensa na sala de aula.

A maior preocupação desses artigos é tentar diminuir o descompasso entre a Historia produzida na academia e aquela ensinada na escola. Por exemplo os trabalhos de Camargo (1997) e Savieto (1997) reconhecem as dificuldades do historiador em geral no trato das imagens. "Os historiadores tem dificuldade para se trabalhar a fonte material e essa dificuldade chega ao ensino de História. A fonte material ou iconográfica são utilizadas como meras ilustrações, que tem a função apenas de confirmar as informações anteriormente obtidas através das fontes escritas". (Savieto 1997: 483). 
Camargo (1997) constata que a utilização do documento histórico (texto e iconografia) nos livros didáticos e paradidáticos tem duas funções em relação ao texto escrito pelo autor: "ou eram apresentados como acessórios (ilustração, complementos até certo ponto descartáveis) ou como prova (reforçando determinadas afirmações e atribuindo a elas maior veracidade e autoridade" (p.349). Aponta ainda que a multiplicidade de significados e interpretações direcionavam sua leitura por uma via única. "Não raro, os documentos foram diferenciados em função de sua maior ou menor proximidade com a "verdade histórica"', (p.349).

Percebemos, assim, uma mudança de postura em relação àquelas obras que propunham uma receita para ensino de história. Nesses artigos, o uso da imagem na sala de aula não aparece mais como um meio para se atrair os alunos para a disciplina ou como uma maneira de se visualizar o passado. A imagem ganha peso documental e deve ser usada na produção do conhecimento histórico. "Nesse sentido, o trabalho com a fonte material... deve ser mais o de enfatizar o método - a percepção dos objetos, a elaboração de hipóteses a partir das evidências, a discussão sobre a possibilidade ou não de se conhecer o passado "tal como ocorreu" - do que a ilustração de um conhecimento já previamente trabalhado em sala de aula proveniente unicamente de fontes escritas" (Savieto 1997: 482).

\section{B. Trabalhos de análise}

Estes são trabalhos que não sugerem ou pretendem ensinar como lidar com as imagens em sala de aula. São trabalhos historiográficos, que vão averiguar como as imagens foram usadas em contextos específicos do ensino de História. O suporte mais comum nesse tipo de trabalho é a tese acadêmica, embora existam alguns artigos e livros que também analisam usos específicos da imagem no ensino de História.

Em sua maioria esses trabalhos vão tratar de questões relacionadas à ideologia no ensino de História. São trabalhos que vão analisar, por exemplo, como o índio, o negro, a mulher e os diferentes segmentos sociais são representados no livro didático ou como a História da América é tratada no ensino de História. Nesses 
trabalhos, o foco não está necessariamente na imagem e sim no assunto mais geral (o negro, o índio, a mulher). "Estes trabalhos não se fixam na ilustração e sim no conjunto da obra didática " (Bittencourt 1993: 295).

Via de regra, a conclusão a que chegam esses autores é de que os livros didáticos ou, de forma mais geral, o ensino de História, transmitem a ideologia da elite dominante e que não há conhecimento neutro, o que, infelizmente, não é nenhuma novidade teórica.

O uso da imagem é sempre criticado neste tipo de obra. Eles constatam o uso exclusivamente motivador e ilustrativo das imagens. Zundt, por exemplo, afirma que :

"quanto às imagens, sua utilização como fonte, se por um lado tem estimulado muitas reflexões, por outro, ainda é restrita e equivocada na prática de ensino de História. Elas tem sua importância aumentada cada vez mais no livro didático, assumindo a função de torná-lo mais atraentes e agradáveis aos olhos de jovens estudantes desacostumados à leitura, ou mesmo de professores, pois o volume de História dos PCNs (Parâmetros Curriculares Nacional), também foi ilustrado com fotos e imagens pictóricas, sem os devidos créditos. Estes materiais incorporam algumas idéias cristalizadas sobre seu uso, como: a imagem ilustra um fato tornando-o mais compreensível para o leitor, ou a imagem ajuda a fixar conteúdos. Além disso, elas fazem parte de implicações político-ideológicas" (2001:135).

Silva (2000: 107, 108) percebe que a "iconografia desempenha um papel central na constituição da memória coletiva, construída e divulgada através da cultura histórico escolar" , e que "os livros didáticos reproduzem um repertório de gravuras, mapas, ilustrações, etc, que são partes do imaginário coletivo, por meio do qual são criadas relações identitárias entre os integrantes do Estado-Nação"

Almeida Neto (1996:96), nota que se as imagens forem usadas como estereótipos e simplificadas, "podem banalizar a didática e empobrecer o conteúdo.

Nestes trabalhos, o que acaba ocorrendo é que a maneira como a crítica ao uso ideológico da imagem é feita, transforma essa crítica em uma ilustração da crítica mais ampla, sobre a imposição da ideologia da elite dominante no ensino. Ou seja o uso ilustrativo e ideológico da imagem é usado como ilustração do uso ideológico do ensino. 
A única crítica dirigida aos responsáveis pela aprovação e circulação destes livros (especialistas do PNLD ${ }^{18}$, MEC) foi feita por Zundt (2000), que percebe, ao analisar os PCNs e editais de convocação para o PNLD, que para estes a imagem é apenas um complemento do texto escrito. Ela percebe também que, hoje em dia, os autores de livros didáticos tem preocupações com o uso que farão das imagens (por exemplo na introduções dos livros e nos manuais dos professores, o uso da imagem como ilustração é condenado e a ampliação das fontes documentais para o ensino de história é defendida), mas que essas preocupações não chegam a ser postas em prática no livro propriamente dito (onde o uso da imagem permanece ilustrativo). Critica também o fato dos livros didáticos não darem um tratamento às imagens condizente ao que a pesquisa histórica tem referendado, "não dando a oportunidade aos alunos de entenderem que também as imagens devem ser lidas e interpretadas" (Zundt 2000:144).

Outras preocupações apresentadas nestes trabalhos dizem respeito ao fato do Livro Didático ser um produto da indústria cultural e portanto mercadoria, obedecendo à evolução das técnicas de fabricação e comercialização pertencentes à lógica de mercado. Com isso, muitas vezes o autor do livro didático não é quem determina que imagens serão usadas em seu livro (por motivos de copyright, por exemplo), como aponta Bittencourt (1997:77).

\footnotetext{
"A diagramação e paginação do livro, são estabelecidas por um profissional especializado e, dessa forma, os caracteres, a dimensão, as cores das ilustrações enfim são decisões de técnicos, de programadores visuais, sendo que o autor, pouco ou nada interfere, na maior parte das vezes, na composição final do livro" (grifo nosso).
}

Hoje em dia, na maioria das grandes editoras, existe até mesmo um especialista em pesquisa iconográfica responsável pela escolha das imagens que irão compor o livro.

\footnotetext{
${ }^{18}$ Programa Nacional do Livro Didático, o organismo responsável pela avaliação, compra e distribuição dos livros didáticos do Governo Federal.
} 
É mais um indício de que a imagem em nada se relaciona ao texto para esses autores e editoras, tendo como únicas funções o embelezamento do livro e a ilustração dos temas apresentados. É a divulgação do conhecimento e a educação se rendendo às normas editoriais.

Parte consistente desses estudos é de difícil utilização e de escasso benefício, em função de amostragens sem critério, decorrentes de um projeto que visse, no livro didático, por exemplo, documentos a serem analisados e, portanto, passíveis de seleção não aleatória. A maior parte deles nem mesmo se preocupa em traçar o trajeto percorrido para se chegar ao material objeto de análise.

A principal restrição que poderia ser feita a esses estudos prender-se-ía à subjetividade das amostragens trabalhadas, que não apenas prejudicam a aferição dos pontos abordados pelos autores de tais estudos como, sobretudo, impedem que qualquer outro trabalho prossiga a partir desses.

Um fato interessante a ser notado é que as maiores críticas que esses trabalhos historiográficos fazem em relação ao uso das imagens dizem respeito exatamente aos usos sugeridos e defendidos naqueles trabalhos do tipo "guia" ou "receita", comuns até os anos 1970 e analisados no item anterior.

Embora esses trabalhos critiquem a maneira como a imagem é utilizada nos livros didáticos, eles não apresentam ou sugerem uma alternativa a esse uso ideológico e ilustrativo.

\section{Relatos de Experiência:}

Neste grupo estão compreendidos os trabalhos que relatam o resultado da aplicação de projetos específicos sobre o uso de imagens no ensino de História. São estudos de casos particulares, apresentados em seminários e congressos ou até mesmo teses. Um exemplo é o trabalho da Luporini, que relata uma experiência com uma classe de oitava série do ensino fundamental. O objetivo desse trabalho era mostrar como é possível aumentar o interesse dos alunos de primeiro grau para com a História, a partir de uma "metodologia viva", diferente da tradicional, fazendo com que o aluno assuma o papel do historiador para estudar a realidade local. 
Este tipo de trabalho é interessante por mostrar o lado prático do ensino. Não é exclusivamente teórico, explicitando os meios de aplicação da proposta metodológica. São os únicos trabalhos que apresentam, além da preocupação teórico-metodológica (como se utilizar a imagem na sala de aula), um resultado prático (as dificuldades e facilidades encontradas na aplicação do projeto, a participação dos alunos no desenvolvimento do projeto, etc.).Em outras palavras, eles apresentam a elaboração da proposta metodológica, a aplicação deste projeto e os resultados dele.

Percebemos, com isso, que os historiadores brasileiros do fim do século passado e início do atual, vem percebendo as falhas no uso das imagens no ensino de História, denunciando o uso ideológico e meramente ilustrativo das imagens, ao contrário do que faziam seus colegas dos anos 1930-70, que defendiam essas formas de uso. Infelizmente, essas constatações tem tido poucas repercussões no meio editorial escolar, pois os livros didáticos continuam fazendo uso das imagens de forma ineficiente.

Infelizmente, estas preocupações ainda são elementares e dizem respeito, principalmente, ao uso ideológico das imagens e sobre a ampliação das fontes documentais para o ensino de História. As preocupações são em relação às fontes visuais e não problemas visuais, o que empobrece e muito o ensino da História (Meneses 2003). Além disso, essas preocupações ainda não romperam a barreira do mundo acadêmico, não comparecendo nos livros didáticos.

A principal utilização dos desenhos atuais pelos autores dos livros analisados é semelhante à utilização, por parte desses mesmos autores, das figuras negras e vermelhas que decoram os recipientes de cerâmica gregos (vide acima p.68): ilustrar o texto e dessa maneira propiciar ao leitor uma "visualização do passado".

Os desenhos atuais são, portanto, utilizados pelos autores como "fotografias do passado" nas quais os leitores podem "assistir" o passado como ele "teria ocorrido". Evidentemente, toda a mediação de séculos de construção de nossa "percepção histórica", que moldou a visão que hoje se tem do passado, não é considerada e nem mesmo acenada ao se fazer tais "fiéis reproduções". 
Para os autores dos livros analisados em nossa amostragem, além de propiciar a visualização do passado, os desenhos atuais parecem ter outra função: a de aproximar as sociedades do passado às do presente. Ao mostrar em desenhos que, por exemplo, um grupo neolítico mantinha um comportamento parecido com os das sociedades atuais (uma mãe afetuosa cuidando de sua prole, um bando de caçadores guiados por seu fiel cão, as mulheres cuidando do trabalho doméstico enquanto os homens caçam e pescam) os autores tentam "humanizar" nossos antepassados.

Em outras palavras os autores utilizam os desenhos atuais para mostrar aos leitores que as civilizações do passado eram tão "humanas" como as do presente e que os valores atuais já existiam no passado. Essa postura por parte dos autores é prejudicial ao entendimento das culturas do passado, que tinham características próprias e não eram apenas uma versão inacabada e rude das culturas do homem moderno. A maneira como essas imagens são apresentadas pode levar o leitor a acreditar que as únicas diferenças entre as sociedades do passado e do presente dizem respeito a questões tecnológicas. Tal postura, claramente, tanto pode enaltecer o presente quanto romantizar o passado como um momento de inocência e pureza.

Constatamos, então, que os autores dos livros analisados perpetuam um uso das imagens no ensino de história bastante sofrível, por sua leviandade, e cuja falta de densidade já vem sendo criticada há muito tempo. Dessa maneira acabam revelando não estarem inteirados a respeito das discussões acadêmicas sobre o assunto, além de considerarem a cultura material como simples juntada a algo por eles considerada como maior, que é a escrita da história a partir dos textos. 


\section{Capítulo IV - Conclusões}

\section{Por uma possível leitura da Cultura Material.}

Como indicamos no capítulo anterior, os historiadores brasileiros do fim do século $X X$ e início do $X X I$ vêm percebendo as falhas no uso das imagens no ensino de História, denunciando o uso ideológico e meramente ilustrativo das imagens, ao contrário do que faziam seus colegas dos anos 1930-70, que defendiam essas formas de uso.

Infelizmente estas preocupações ainda são elementares, se comparadas às preocupações e às novas tendências de pesquisa apresentadas por estudiosos da Cultura Material na Europa e nos EUA ${ }^{19}$, e dizem respeito, principalmente ao uso ideológico das imagens e à ampliação das fontes documentais para o ensino de História. As preocupações são em relação às fontes visuais e não a problemas visuais. Quero dizer com isso que a preocupação está apenas em ampliar os tipos de fontes que o historiador deve consultar e não ampliar os problemas e questões da pesquisa histórica, diversificando-os.

Além da abordagem da cultura material como documento histórico, enquanto a academia não responder ao chamado da necessidade urgente de se deslocar o

\footnotetext{
${ }^{19}$ Por exemplo: Beaudry, M.C.; Cook, L.; Mrozowski,S.,1991, "Artifacts and active voices; material culture as social discourse" in Mcguire and Paynter(Eds), The archeology of inequality, Oxford, Blackwell; Hall,M.,1991, "High and low in townscape of Dutch South America and South Africa: the dialectics of material culture", in Social Dynamics, 17(2); Harrison,R.,1989, "Nonverbal communication" in King, S. (ed), Human Communication as a field of study. New York, State University of New York Press; Hodder, I. (ed.), 1989, The Meaning of things: material culture as a symbolic expression. Londres, Unwin Hyman; Miller, D. \& Tilley, C., 1984, "Ideology power, material culture and long-term change." In Miller, D. \& Tilley, C. Ideology, power and pre-history. Londres, Cambrigde University Press; Ross, A., 1994, "The ecology of images." in Bryson, N; Holly, M; Moxey, K., Visual culture Images and interpretations. Hanover, Wesley Press; Rouesnel, L.F., 2001, "French Anthropology and Material culture", in Journal of Material Culture, 6(2): 237-247;

Yentsch, A. \& Beaudry, C.,2001, "American Material Culture in mind, thought and deed", in Hodder, I. (Ed.),2001, Archeological theory today. Polity Press.
} 
interesse dos historiadores, das fontes visuais (iconografia, iconologia), para um tratamento mais abrangente da visualidade como uma dimensão importante da vida social e dos processos sociais, como vem sendo apontado por Meneses (2003: 11), a nova abordagem dificilmente chegará ao ensino de História.

Acreditamos que os problemas que apresentamos relacionados ao uso da cultura material por parte dos autores dos livros analisados têm origem em falhas na própria formação acadêmica desses autores.

Ao analisarmos essa formação, percebe-se quão notável é a grande influência de Fernand Braudel e Sérgio Buarque de Holanda na historiografia brasileira referente à cultura material. As obras Civilização material e capitalismo (1967), de Braudel, e Caminhos e fronteiras (1956), de Buarque de Holanda, são referências constantes na historiografia brasileira e tem servido de modelo para o trabalho com a cultura material, assim difundindo uma abordagem típica dos anos 40 que os especialistas em cultura material afastaram desde os anos 70 do século XX.

O grande problema é que a visão de Cultura Material destes autores passa, evidentemente, ao lago da moderna teoria da cultura material: ambos buscam entender a cultura material a partir de textos e não a partir dela própria, usando-a meramente como ilustração do texto que a explica. Ou seja, a cultura material é usada como ilustração até mesmo quando o assunto é a própria cultura material.

A falta de familiaridade dos historiadores brasileiros com os estudos de cultura material não apenas ainda não gerou, até hoje, nenhuma crítica sistemática em relação a esta visão empobrecedora da cultura material, como, pelo contrário, essa visão é defendida e valorizada, como por exemplo, no prefácio à nova edição de Caminhos e fronteiras, na qual Fernando Novais exalta a visão braudeliana avant la lettre de Buarque de Holanda em relação à cultura material ( $3^{A}$ edição, 1997), revelando total desconhecimento da bibliografia especializada e, com isso, descaso patente para com o tema.

O peso da autoridade desses autores acaba sendo determinante para que os mais jovens os aceitem sem questionamentos, salvo se forem formados especificamente em outra vertente. 
Assim, essa postura de estudar a cultura material a partir dos textos, criticada há mais de 30 anos pelos especialistas, ainda é presença freqüente no ambiente acadêmico brasileiro. Uma análise dos programas dos cursos de graduação e pósgraduação do departamento de História da FFLCH da Universidade de São Paulo nos anos de 2003-2006 mostrou que as novas tendências nos estudos de cultura material ainda não fazem parte das preocupações do corpo docente. Menos de $10 \%$ dos cursos oferecidos pelo departamento trabalham com essas recentes tendências, apresentando e discutindo as questões metodológicas e as recentes propostas do trabalho com a cultura material, buscando formar os alunos no trato conjunto de textos e cultura material para a produção do conhecimento histórico.

Constatamos assim que, com certeza na USP e, rastreando a produção acadêmica, também nas outras universidades, as novas tendências nos estudos de cultura material ainda não estão sedimentadas no ambiente acadêmico, responsável pela formação dos futuros pesquisadores, professores e autores de livros didáticos o que inevitavelmente fará com que essas novas tendências continuem excluídas do ensino fundamental de História. É, portanto, necessária, a incorporação das novas tendências historiográficas (não só aquelas diretamente relacionadas à cultura material) pelo ambiente acadêmico brasileiro, que ainda dedica muito tempo e atenção ao estudo e à reprodução das ideais dos cânones historiográficos dos anos 1930-50.

As falhas na formação dos autores dos livros analisados em nossa amostragem, decorrentes da não incorporação das novas tendências historiográficas pelo ambiente acadêmico, não é a única causa do tratamento inadequado dado à cultura material nos livros analisados. Os critérios apresentados para seleção dos livros (vide acima p.) fez com que esse problema fosse institucionalizado devido ao fato do MEC desconsiderar a importância da discussão das fontes históricas. Se os responsáveis pela avaliação dos livros didáticos incluíssem a cultura material entre as fontes a serem discutidas e acrescentassem a discussão de fontes como quesito excludente, os autores seriam levados a preencher lacunas de sua própria formação. 
Existe aqui uma contradição. Os PCNs instruem os professores a usarem diferentes tipos de documentos históricos explicando que as mais diversas obras humanas produzidas nos mais diferentes contextos sociais e com objetivos variados podem ser chamados de documentos históricos.(MEC 1998). A contradição está no fato de, ao mesmo tempo, instruir professores a trabalharem com diferentes formas de documentos e aprovar e fornecer livros didáticos que não necessariamente discutem tais fontes históricas.

O termo cultura material não aparece no guia de avaliação. O termo utilizado é sempre "ilustração", revelando que a falta de atualização sobre as mais modernas tendências dos estudos historiográficos parte do próprio solicitante.

No capítulo anterior fizemos um levantamento do uso da cultura material pelos autores dos livros didáticos brasileiros. Foram apontadas diversas características da apresentação das imagens de cultura material que empobrecem e prejudicam a análise, por parte dos leitores, do fenômeno material do passado.

Embora nosso objetivo não seja o de potificar sobre como se usar a cultura material na escrita da história, algumas sugestões para o que julgamos ser um dos possíveis tratamentos adequados á questão podem ser avançados. Não pretendemos fazer um guia de como a cultura material deveria ser utilizada nos livros didáticos e tampouco afirmar que a única maneira de se trabalhar a cultura material seja a por nós sugerida. Trata-se apenas de sugestões que, acreditamos, poderiam enriquecer o livro didático brasileiro, procurando mostrar como seria possível, didaticamente, usar objetos como documento histórico, introduzindo a questão da cultura material de maneira básica, mas sólida.

Um bom início é comparar a utilização da cultura material nos livros didáticos com o uso proposto em dois livros para-didáticos ( $A$ Mesopotâmia e A Grécia Antiga - ambos escritos por Marcelo Rede para a coleção Que História é Essa, da Editora Saraiva, publicados respectivamente em 1997 e 1999) que apresentam uma abordagem diferenciada da cultura material, tendo como público alvo os mesmos alunos do ensino fundamental. Sabemos que o processo de criação de um livro didático e de um para-didático são bastante diferentes e obedecem regras distintas e que o autor dos para-didáticos tem uma maior liberdade em seu trabalho. Mesmo 
assim, acreditamos que as sugestões que iremos propor a partir de exemplos retirados dos para-didáticos podem ser aplicadas nos livros didáticos brasileiros.

Em primeiro lugar, as obras para-didáticas mencionadas, por exemplo, apresentam um número reduzido de desenhos atuais (apenas $6 \%$ das imagens no livro sobre a Mesopotâmia), informam os locais de origem e os locais onde estão hoje os vestígios arqueológicos e não tratam as imagens como uma simples ilustração ao texto, propondo uma série de exercícios e discussões que possibilitam, de maneira didática, um melhor entendimento das fontes e documentos históricos, não induzindo os alunos a acreditarem em uma supremacia das fontes escritas sobre a cultura material.

Assim sendo, a questão da melhoria das legendas - apresentação obrigatória da dimensão, local de origem e cronologia do contexto onde foi encontrado o vestígio arqueológico - é a nossa primeira sugestão, já que não se trata de simples legendamento mas, na realidade, a apresentação básica dos objetos aos leitores.

Infelizmente a preocupação apresentada pelo autor dos livros para-didáticos supracitados em relação à cultura material não é uma característica presente em todos os livros para-didáticos. Não é o objetivo dessa dissertação fazer uma análise da presença da cultura material em livros para-didáticos, mas como esse tipo de literatura tem como alvo o mesmo público dos livros didáticos analisados sentimos a necessidade de fazer uma pequena averiguação deste universo. Foram analisados 11 títulos, todos referentes à História Antiga e todos escritos por professores universitários. $^{20} \mathrm{O}$ resultado da análise mostrou que o tratamento dado à cultura material nesses livros não é muito diferente daquele encontrado nos livros didáticos de nossa amostragem. Com exceção dos livros de Cardoso e de Rede, esses livros também fazem um uso meramente ilustrativo da cultura material. Digno de nota é o livro Os primeiros habitantes do Brasil, de Norberto Guarinelo, que em sua capa

\footnotetext{
${ }^{20}$ Cardoso, C. ,1988, Sociedades do Antigo oriente próximo. Atica, São Paulo; Cardoso, C., 1987, A Cidade Estado Antiga. Atica, São Paulo; Cardoso, C., 1990, Antiguidade Oriental: política e religião. Contexto, São Paulo; Cardoso, C. 1982, O Egito Antigo.Brasiliense, São Paulo; Corassin, M. Sociedade e política na Roma antiga. Atual, São Paulo; Florenzano, M. 1982,O mundo antigo: economia e sociedade. Brasiliense, São Paulo; Funari, P. 1989, Cultura popular na antiguidade clássica. Contexto, São Paulo; Funari, P. 2005, Grécia e Roma. Contexto, São Paulo; Guarinelo, N., 1994, Os primeiros habitantes do Brasil. São Paulo, Atual. Pinsky, J. As primeiras Civilizações. Contexto, São Paulo;
} 
apresenta a seguinte frase: "a cultura material de nossos antepassados". Infelizmente não é exatamente isto que encontramos no conteúdo do livro. O número de desenhos atuais presentes nesse livro é enorme, apresentando uma porcentagem notavelmente maior que aquela dos didáticos analisados. Estes desenhos atuais correspondem a $82 \%$ das imagens presentes no livro, não são apresentados em escala e tampouco explicitam as dimensões dos artefatos e estruturas urbanas e rurais que representam. Temos, por exemplo, o desenho de uma urna funerária marajoara apresentada do mesmo tamanho que pontas de flecha da "tradição umbu", levando ao engano de se acreditar que ou a urna é miniaturística ou a flecha é gigantesca.

Além disso, o principal uso dessas imagens por parte do autor é a de ilustrar o texto, respondendo às suas referências à engenhosidade e criatividade dos habitantes do Brasil pré-colonial no que diz respeito à produção de artefatos e estruturas urbanas e rurais que possibilitavam e facilitavam a sobrevivência desses. O livro também se propõe a mostrar as particularidades materiais dos povos que habitavam as diversas regiões do Brasil mas com os vestígios matérias dessas culturas reduzidos a desenhos atuais extremamente semelhantes, não se dá ao leitor nenhuma possibilidade de perceber as características próprias de cada cultura.

É interessante notar que esse livro faz parte da bibliografia de $20 \%$ dos livros analisados e 6 desenhos atuais produzidos para esse para-didático aparecem em livros didáticos analisados em nossa amostragem. Ou seja, este para-didático vem servindo de referência até mesmo para os autores dos livros didáticos, mesmo não utilizando a cultura material a contento.

Como útil exemplo piloto do uso didático da cultura material, podemos citar um exemplo retirado do livro citado acima $A$ Mesopotâmia (Rede 1997). Ao falar sobre as mudanças tecnológicas na região no final do Paleolítico, o autor apresenta duas imagens: a primeira contém a foto de 5 instrumentos neolíticos feitos de pedra, achados na região da Mesopotâmia e a segunda contém a foto de 4 instrumentos metálicos encontrados na mesma região. No corpo do texto o autor instiga o leitor a comparar as duas imagens e a perceber as diferenças entre os instrumentos de cada imagem. Com isso o leitor tem a oportunidade de, ele mesmo, notar as 
características desses instrumentos, pensar em suas formas de utilização e funções, suas diferenças e semelhanças, sem ser dirigido por um discurso fabricado pelo autor e, dessa maneira, começa a desenvolver sua própria percepção da cultura material, construindo seus próprios descritores e tornando viável as discussões sobre a cultura material como documento histórico.

Outro exemplo, apresentado no mesmo livro, mostra como é possível a utilização de mediações interpretativas de maneira didática. O autor apresenta um desenho da Mesopotâmia feito por Layard no século XIX. Na legenda o autor explica que essa imagem foi feita no século XIX e mostra uma visão fantasiosa e romântica da antiga Mesopotâmia, visão essa que era comum na época das primeiras escavações na região. Dessa maneira o leitor pode compreender que aquela imagem não é a realidade mesopotâmica na antiguidade e sim a visão dos estudiosos e artistas do século XIX sobre aquela região. A apresentação de tal visão, quando analisada e comparada com os conhecimentos atuais,auxilia sobremaneira a discussão historiográfica, tão vital e ainda deficitária no ensino da história entre nós, pois oferece, de maneira perfeitamente compreensível, leituras datadas e a factibilidade de compreendê-las.

A utilização da cultura material do presente também pode ser de grande interesse para a discussão da cultura material do passado. O entendimento de questões como valor simbólico dos objetos, descarte, formação do sítio arqueológico, diferenças culturais, interação cultural e modismos pode ser facilitado com a introdução de exemplos de cultura material mais próximos aos alunos. Nesse sentido, a discussão de marcas atuais, seu significado em diferentes segmentos da sociedade e a publicidade que as envolve pode ser um consistente instrumento de trabalho para o professor. Além disso, ao discutir questões atuais e questões de semelhante natureza no mundo antigo, o professor estaria dando ao aluno a percepção da importância dos estudos históricos de maneira geral.

Outra sugestão seria a introdução, no manual dos professores, de um guia metodológico para a utilização da cultura material. O objetivo desse guia seria o de colocar o professor em contato com as mais recentes tendências nos estudos de 
cultura material e dessa maneira tentar diminuir o fosso existente entre conhecimento acadêmico e o conhecimento escolar.

A presença de exercícios relacionados à cultura material também pode enriquecer o ensino de História. Esses exercícios podem ser teóricos (discussão das fontes históricas, discussão das necessidades do homem, pesquisas bibliográficas,etc) e práticos (oficina com objetos, trabalhos de descrição e comparação de objetos e estruturas urbanas e rurais, reprodução de objetos,etc).

Percebemos então que o tratamento dado à cultura material nos livros didáticos analisados é bastante superficial e pobre. A principal função das imagens de cultura material nos livros didáticos ainda é a de ilustrar o texto.Paradoxalmente, a mesma tendência texto-centrada considera o livro que contenha poucas imagens, "cansativo" e apela para o apoio da imagem como "diversão".

Ousamos sugerir, portanto, que a Academia vem formando profissionais de maneira deficiente e com abordagem ultrapassada. Tais profissionais, sem nenhuma sensibilidade e formação para a produção da história com uso combinado de documentos escritos e de cultura material, ao ocupar postos determinantes no MEC, solicitam livros didáticos dentro de sua concepção deficiente e os livros acabam fatalmente correspondendo à solicitação, filhos fiéis de autores que reproduzem o mesmo quadro de sua formação textocentrista nos livros didáticos que produzem.

Enquanto a Academia não for sensibilizada para a necessária mudança, ao ritmo de $10 \%$ de cursos-ano, como mencionado acima, o quadro é, infelizmente, bastante sombrio.

Esperamos que a presente dissertação possa servir, de alguma maneira, para suscitar reflexão e induzir a movimento de mudança que, por menor que seja, já terá justificado o empenho dedicado neste trabalho. 


\section{Referências Bibliográficas}

ABUD, K., 1984, O livro didático e a popularização do saber histórico .in SILVA, M. Repensando a História. Rio de Janeiro, Ed. Marco Zero.

AMALVI, C.c 1988, De'lart et de la maniere d'accommender les héros de l'histoire de France: de Vercingetorix à la revolucion. Paris, Albert Michel.

ANDRADE, M., 2000, A vida comum: espaço e cotidiano nas representações urbanas da Atenas clássica. Tese de doutorado, São Paulo, FFLCH-USP.

BEAUDRY,M.C.; COOK,L. ;MROZOWSKI,S.,1991, "Artifacts and active voices; material culture as social discourse" in McGUIRE and PAYNTER(Eds), The archeology of inequality, Oxford, Blackwell.

BITTENCOURT, Circe. 1993, Livro didático e conhecimento histórico: uma história do saber escolar. Tese de doutoramento, São Paulo, FFLCH-USP.

1997, "Livros didáticos entre textos e imagens", in BITTENCOURT, C.(org),O saber histórico na sala de aula. São Paulo,Contexto.

BRANDÃO, Z., 1999, A intelligentsia educacional. Um percurso com Paschoal Leme. Bragança Paulista, EDUSF.

BRAUDEL.F., 1970, Civilização material e capitalismo, tomo I, Lisboa, Ed Cosmos.

BRONNER, S., 1986, Grasping Things: Folk Material Culture and Mass Society in America. Lexington, University of Kentuky Press.

BURGOON, M. and RUFFNER, R., 1978, Human Communication. New York, Holt, Rinehart and Winston. 
CARMO, S., 1991, Entre a cruz e a espada: O índio no discurso do livro didático de História. Dissertação de mestrado, São Paulo FE-USP.

CARRANDINI.A.,1979, Archeologia e Cultura Materiale. Bari, De Donato Editore.

CHILDE, V., 1966, A evolução cultural do homem. Rio de Janeiro, Zahar.

CHOPPIN, A. 2004, História dos livros e das edições didáticas: sobre o estado da arte. In Educação e pesquisa 3 (30)

CONRAD, G., 1981, Cultural materialism... American Anthropologist, 46(1):2-26.

DAVIES, N. 1988, "As camadas populares nos livros de História do Brasil",. in PINSKY, J., O ensino de História e a criação do fato. São Paulo, Contexto.

DAVIES, N., 1996, "Livro didático: Apoio ao professor ou vilão do ensino de História?' in: Anais do $2^{\circ}$ Encontro Perspectivas do ensino de História. São Paulo, FEUSP.

DEETZ, J., 1977, In small things forgotten: An archeology of Early American life. New York, Doubleday.

DEETZ, J. , DETHLEFSEN, E. Death's head, cherub, urn, and willow. in Natural history, 76(3).

DEETZ, J.,1977, "Material Culture and archeology: What's the difference?", in FERGUSON, L. (Ed), Historical Archeology and the importance of material things. The Society for historical archeology, Special Publication series $n^{0} 2$.

DOUGLAS, M. \& SHERWOOD,B., 1979, The World of Goods. Londres, Allen Lane. 
DUBY, G., 1988, Economia rural e a vida no campo no ocidente medieval. Lisboa, Ed. 70.

FARIA, A., 1984, A ideologia no livro didático. São Paulo, Cortez Editora.

FRANCO, M.L.P.,1981, História do Brasil: a versão fabricada nos livros didáticos de $2^{\circ}$ grau. São Paulo, PUC-SP.

1982, O livro didático de história no Brasil; a versão fabricada. São Paulo, Global.

FREITAG, B.;MOTTA,V.; COSTA, W., 1989, O Estado da arte do livro didático no Brasil. Brasília, Reduc.

FREITAS, M.C.1999, Memória intelectual da educação brasileira. Bragança Paulista, EDUSF.

GEERTZ, C., 1973, The interpretation of cultures. New York, Basic Books.

GLASSIE, H., 1975, Folk housing in Midle Virginia: A structural analysis of históric artefacts. Knoxville, University of Tennesee Press.

GODINHO, H., 1999, "História, educação e imagem." in ARAÚJO, A; MAGALHÃES, J. História, Educação e Imaginário.Universidade do Minho.

GOFFMAN, E., 1959, The Presentation of Self in Everyday Life. Garden City, Double Day.

Guia de livros didáticos- $5^{a}$ a $8^{a}$ séries., 2000, Ministério da Educação e do Desporto, Brasília, MEC/PNLD. 
HALL,M.,1991, "High and low in townscape of Dutch South America and South Africa: the dialectics of material culture", in Social Dynamics, 17(2).

HANNEMAN, G.,1975, "The study of human communication", in MAcEVEN \& HANNEMAN (eds), Communication and Behavior. Ma, Addison Wesley.

HARRISON,R.,1989, "Nonverbal communication" in KING, S. (ed), Human Communication as a field of study. New York, State University of New York Press.

HARRISON R. \& CROUNCH, W., 1975, "Nonverbal communication: Theory and research." in MAcEVEN \& HANNEMAN (eds.), Communication and Behavior. Ma, Addison Wesley.

História do Livro didático 1995-2001. 2001, Ministério da Educação e do Desporto, Brasília, MEC/PNLD.

HODDER, I., 1982, Symbols in Action, London, Duckworth.

HODDER, I. (ed.), 1989, The Meaning of things: material culture as a symbolic expression. Londres, Unwin Hyman .

KAPLAN, D. \& MANNERS,A ., 1975, Teoria da Cultura. Rio de Janeiro, Zahar.

KILIZTAJN, I.A .,1997, História e memória nos manuais didáticos. Tese de mestrado, São Paulo FE-USP.

KOSSOY, B. 1989, "Análise e interpretação do documento fotográfico: Novas abordagens." in Anais do seminário Perspectivas do ensino de História. São Paulo, FE-USP.

KRAMER, S., 1972, Os Sumérios. Lisboa, Livraria Bertrand 
LACERDA, A., 2000, "Fotografia e propaganda: Capanema e o projeto editorial "obra Getuliana"., in GOMES, A.C., Capanema: o Ministro e seu ministério.Bragança Paulista, FGV Editora.

LAVISSE, E.,1887, Histoire de France: course elementaire. Paris, Arcolin.

LE GOFF, J., 1983, A civilização do ocidente medieval vol I. Lisboa, Editorial Estampa. ., 1990, História e Memória. São Paulo, Unicamp.

LEROI-GOURHAN, A., 1980, Arte y grafismo en la europa prehistorica. Madrid, Istmo. , 1982, Simbolos, artes y creencias de la prehistoria. Madrid, Istmo.

LINS, O.,1977, Do ideal e da glória: Problemas inculturais brasileiros. São Paulo, Summus.

McCRACKER, G., 1988, Culture and Consuption. Bloomington, Indiana University Press.

McNAIRN, B., 1980, The method and theory of V. Gordon Childe. Edinburg, Edinburg. University Press.

MEKSENAS, P., 1992, A Produção do livro didático: Sua relação com o Estado, autor e editor. Tese de mestrado. São Paulo FE-USP. 
MENESES, U.T.Bezerra de, 1980, "O objeto material como documento", Manuscrito de aula ministrada no curso "Patrimônio cultural: políticas e perspectivas", organizado pelo IAB/CONDEPHAAT .

., 1983 "A cultura material no estudo das sociedades antigas." in Revista de História nova série n 115.

.,1992, "História cativa da memória? Para um mapeamento da memória no campo das ciências sociais". in Revista do IEB n 34, São Paulo.

.,1993, "Pintura histórica: documento histórico?" in MENESES et alii, Como explorar um museu histórico. Museu Paulista, São Paulo.

., 1994, Do teatro da memória ao laboratório da história: a exposição museológica e o conhecimento histórico. in Anais do Museu Paulista nova série vol 2, São Paulo.

, 2003, Fontes visuais, cultura visual, história visual.

Balanço provisório, propostas cautelares. In Revista Brasileira de História, n. 23, n. 45.

. O museu como "espaço de ficção" . No prelo.

MILLER, D. \& TILLEY, C., 1984, “Ideology power, material culture and long-term change." In MILLER, D. \& TILLEY, C. Ideology, power and pre-history. Londres, Cambrigde University Press.

MILLER, D., 1987, Material Culture and Mass Consuption .Londres, Basil Blackwell. 
MOLINA, O., 1987, Quem engana quem? Professor x livro didático; Campinas, Papirus.

MORIN, E., 2002, A religação dos saberes, o desafio do século XXI. Rio de Janeiro, Bertrand Brasil.

MUNAKATA, K.,2000, "Não podemos fazer escolas sem livros": Livro didático segundo Anísio Teixeira. In SMOLKA, A.L; MENESES, M.C., 2000, Anísio Teixeira 1900-2000. Provocações em educação. Campinas, Editora Autores Associados.

MULLINS,P., 1996, "Negotiating industrial capitalism: mechanisms of change among agrarian potters. In DE CUNZO,L. \& HERMAN,L. (Eds), Historical archeology and the study of American culture, Winterthur, Winterthur Mmuseum.

,1999, Race and affluence: An archeology of african America and consumer culture. New York, Kluwer Academy/Plenum.

NEVES, E., 1998,Twenty years of Amazonian archaeology in Brazil (1977- 1997). In Antiquity Cambridge, v. 72, n. 277.

1999, Duas interpretações para explicar a ocupação pré-histórica na Amazônia. In TENÓRIO, M. (org) Pré-história da Terra Brasilis. Rio de Janeiro, Editora UFRJ

NOSELLA, M.L., 1981, Bela mentiras: A ideologia subjacente aos textos didáticos. São Paulo, Ed. Moraes.

OLIVEIRA, J.B., 1983, A pedagogia a e a economia do livro didático. Rio de Janeiro, ABT.

OLIVEIRA, A., 1986, O livro didático. Rio de Janeiro, Tempo Brasileiro. 
Parâmetros Curriculares Nacional, História, 1998, Ministério da Educação e do Desporto, Brasília, MEC.

PARRA, N. 1972, Os recursos audiovisuais e a renovação didática. Tese de Doutoramento, FE-USP.

PARRA, N; PARRA, I., 1972, Técnicas audiovisuais na educação. São Paulo, Edibell.

PESEZ.,1978,"Cultura Materiale" IN ENCICLOPÉDIA EINAUDI, Vol 4, Torino, Giulio Einaudi.

PFROMM NETTO., S., 1974, O livro na educação. São Paulo, Editora Primor.

PINSKY, J., 1985, O Estado e o Livro Didático. Campinas, Unicamp.

PINSKY, V.; WYLIE, A.,1984, Critical Traditions in contemporary archeology. Londres, Cambrigde University Press.

POLHEMUS,T.,1978, fashion and anti-fashion. Anthropology of clothing and adornment. London, Thames \& Hudson.

PROWN, J., 1980, "Mind in matter: An introduction to material culture theory and method" in GEORGE, R. (Ed) Material Culture in America 1600-1860.

QUIMBY, I.,1978, Material Culture and the study of American Life. New York, WW Norton.

RATHJE,W.,1979, "Modern Material culture studies". in SCHIFFER, M. Advances in Archeological method and theory vol.2 . Londres, Academic press. 
REDE, M.,1993, "Iconografia, História e Antigüidade Grega: Tendências gerais." in Anais do Museu Paulista, nova série No.1, São Paulo.

.,1996, "História a partir das coisas: Tendências recentes nos estudos da cultura material", in Anais do Museu Paulista nova série, vol 4, São Paulo.

REZNIK, L., 1992, Tecendo o amanhã. Tese de mestrado, Niterói, UFF.

RIBEIRO, M., 2002, Uma abordagem historiográfica da arqueologia das práticas mortuárias. Tese de mestrado, São Paulo, FFLCH-USP.

ROSS, A., 1994, "The ecology of images." in BRYSON, N; HOLLY, M. MOXEY, K. Visual culture Images and interpretations. Hanover, Wesley Press.

ROUESNEL, L.F., 2001, "French Anthropology and Material culture", in Journal of Material Culture, 6(2): 237-247.

SERRANO,J.,1935, Como se ensina a História. Rio de Janeiro, ed. Melhoramentos.

SCHLERETH, Th.(Ed.), 1982, Material Culture Studies in America. AASLH, Nashville, Tennessee.

SCHIFFER, M. B.,1972, "Archeological context and systemic context", in American Antiquity, 37.

SOUTH, S., 1977 Method and Theory in historical archeology. New York, Academy Press.

SPRIGGS, M., 1984, Marxist perspectives in Archeology. Londres, Cambrigde University Press. 
SUANO, M., 2003, The first trading empires : prehistory to c. 1000 BC. In ABUFALA, D.(ed). The Mediterranean in history. London: Thames \& Hudson

SUSSEKIND DE MENDONÇA, E. 1946, A extensão cultural nos museus, Rio de Janeiro, I. O.

TELLES, N., 1984, Cartografia brasílis, ou, Esta história está mal contada. São Paulo, Edições Loyola.

TEIXEIRA, M.C., 1999, “Imaginário e ideário no discurso pedagógico de Anísio Teixeira e Paulo Freire." in ARAÚJO, A; MAGALHÃES, J. , 1999, História, Educação e Imaginário. Universidade do Minho.

TRIGGER, B., 1973, Além da história: os métodos da pré-história. São Paulo, Epu.

VASCONCELLOS, C.; ALONSO, A.; LUSTOSA, P., 2000, A abordagem dp período pré-colonial brasileiro nos livros didáticos do ensino fundamental. in Revista do MAE 10.

VASCONCELLOS, C., 1993, Pré-história brasileira no livro didático de primeiro grau. In TENORIO, M.; FRANCO, T. (orgs) Seminário para a Implantação da Temática pré-história Brasileira No Ensino de Primeiro, Segundo e Terceiro Graus. Rio de Janeiro, Museu Nacional.

XAVIER, L., 1999, O Brasil como laboratório. Bragança Paulista, EDUSF.

YENTSCH,A., 1994, A Chesapake family and their slaves: a study in historical archeology. Cambridge, Cambridge University Press.

YENTSCH, A. \& BEAUDRY, C.,2001, "American Material Culture in mind, thought and deed", in Hodder, I. (Ed.), 2001, Archeological theory today. Polity Press. 
ZUNDT, M. D., 2001, América curricular. Tese de mestrado, São Paulo, FFLCHUSP. 